\title{
Molybdenum alloying in high-performance flat-rolled steel grades
}

\author{
Pello Uranga ${ }^{1}$ - Cheng-Jia Shang ${ }^{2}$ Takehide Senuma ${ }^{3} \cdot$ Jer-Ren Yang ${ }^{4}$. \\ Ai-Min Guo ${ }^{5} \cdot$ Hardy Mohrbacher $^{6,7}$ (D)
}

Received: 28 May 2019/Revised: 29 November 2019/Accepted: 2 December 2019/Published online: 9 January 2020

(C) The Author(s) 2020

\begin{abstract}
Considerable progress in developing flat-rolled steel grades has been made by the Chinese steel industry over the recent two decades. The increasing demand for high-performance products to be used in infrastructural projects as well as in production of consumer and capital goods has been driving this development until today. The installation of state-of-the-art steel making and rolling facilities has provided the possibility of processing the most advanced steel grades. The production of high-performance steel grades relies on specific alloying elements of which molybdenum is one of the most powerful. China is nearly self-sufficient in molybdenum supplies. This paper highlights the potential and advantages of molybdenum alloying over the entire range of flat-rolled steel products. Specific aspects of steel property improvement with respect to particular applications are indicated.
\end{abstract}

Hardy Mohrbacher

hm@niobelcon.net

1 CEIT and TECNUN, University of Navarra, San Sebastian, Spain

2 Collaborative Innovation Center of Steel Technology, University of Science and Technology Beijing, Beijing 100083, People's Republic of China

3 Graduate School for Nature Science, Okayama University, Okayama, Japan

4 Institute of Materials Science and Engineering, Taiwan University, Taipei, Taiwan, People's Republic of China

5 CITIC Metal, Beijing 100027, People's Republic of China

6 Department of Materials Engineering, KU Leuven, 3001 Leuven, Belgium

7 NiobelCon bvba, 2970 Schilde, Belgium
Keywords HSLA steel - Quench \& tempering · Direct quenching · Press hardening - Quenching \& partitioning · Precipitation

\section{Introduction}

Flat carbon steel is one of the most versatile materials used in a large number of industrial applications. The gages of products in this steel family range from $0.5 \mathrm{~mm}$ to over $100 \mathrm{~mm}$. Typical products manufactured from flat steels are vehicles, pipelines, pressure vessels, machines, construction equipment, bridges, offshore platforms, ships, or containers. Most of these items involve a combination of cutting, forming and joining operations during the manufacturing process. These fabrication techniques imply particular requirements towards the steel [1,2]. The quest for increased strength has always been a driving force for steel development over the last five decades. Higher strength allows making structures lighter by maintaining the same load bearing capacity at reduced material gage. Consequently, sustainability and efficiency in terms of raw material consumption, manufacturing time, transport weight and emissions generated along the entire production chain are subjected to continuous improvement. However, increasing the strength of steel can be in conflict with forming and welding operations applied during manufacturing. With regard to the applications, energy absorption capacity, toughness, fatigue resistance and resistance against hydrogen embrittlement are key properties for steels of increased strength. Therefore, particular attention has to be attributed to the alloy concept and microstructural design of steel. The alloy concept dominantly affects the weldability, whereby reducing the carbon content or carbon equivalent (CE) clearly has a positive impact. Steel offers a 
variety of microstructures, which majorly determine its properties. The combination of alloy and process design allows adjusting the microstructure. Regarding process design, thermo-mechanical controlled processing (TMCP) represents the baseline for making high strength steel and is widely used in strip as well as plate rolling. Various cooling strategies at the end of the rolling process or separate heat-treatments are further methods of influencing the microstructure and optimizing properties. For thin-gaged cold rolled products the final microstructure is adjusted by a continuous annealing process incorporating a suitable cooling strategy. Molybdenum as an alloying element has a wide spectrum of metallurgical effects. It can help achieving the desired strength level at reduced carbon equivalent, thus improving weldability. The various interactions of molybdenum during steel processing allow promoting particular microstructural features relevant for manufacturing and final properties. The present paper will give an overview on how molybdenum is used in combination with state-of-the-art processing technology for producing modern high strength steel. For particular products, the resulting benefits with regard to manufacturing processes will be highlighted.

\section{Strengthening mechanisms and processing strategies for high-performance HSLA steel}

The simplest way of raising a steel's strength is increasing its carbon content. However, this approach harms toughness, formability and weldability. Accordingly, since the early 1970's efforts are being done of reducing the carbon content in flat steels while enhancing strength by other mechanisms. Figure 1 identifies the possibilities for increasing strength in low-carbon steel. Besides of a modest effect caused by solid solution strengthening, typically provided by silicon and manganese alloying, grain refinement offers a significant potential for raising strength by 200-300 MPa. This is related to the well-known HallPetch effect [3]. It is particularly advantageous that grain refinement simultaneously lowers the ductile-to-brittle transition temperature (DBTT) [4]. Hence, grain refinement is the only strengthening mechanism being beneficial to strength and toughness. Therefore, grain-refined lowcarbon steel should always be the baseline for any high strength steel development. The standard way of achieving grain refinement is provided by niobium microalloying in combination with TMCP rolling. The mass fraction of $\mathrm{Nb}$ is less than $0.1 \%$. That approach reaches a limit at around $500 \mathrm{MPa}$ yield strength. Steel grades of even higher strength need to involve additional mechanisms such as precipitation or dislocation strengthening. Ultra-fine particles, typically consisting of microalloy $(\mathrm{Nb}, \mathrm{Ti}$, or $\mathrm{V}$ ) carbides and having a size of less than $10 \mathrm{~nm}$, form during or after phase transformation from austenite to ferrite. The dispersed particles are acting as obstacles for dislocations and particularly enhance the yield stress. The precipitation mechanism requires a cooling-stop or coiling temperature in the range of $580-650{ }^{\circ} \mathrm{C}$ to obtain the best result. Depending on the amount of microalloy added, strength can be increased by up to $300 \mathrm{MPa}$. Accelerated cooling and relatively low cooling-stop or coiling temperature promote dislocation strengthening. This mechanism increases strength by about $150 \mathrm{MPa}$. The microstructure then gradually changes from polygonal ferrite to bainite. In addition to high dislocation density, a pronounced substructure of low angle boundaries, which also contributes to grain refinement, is characteristic for bainite [5]. It is
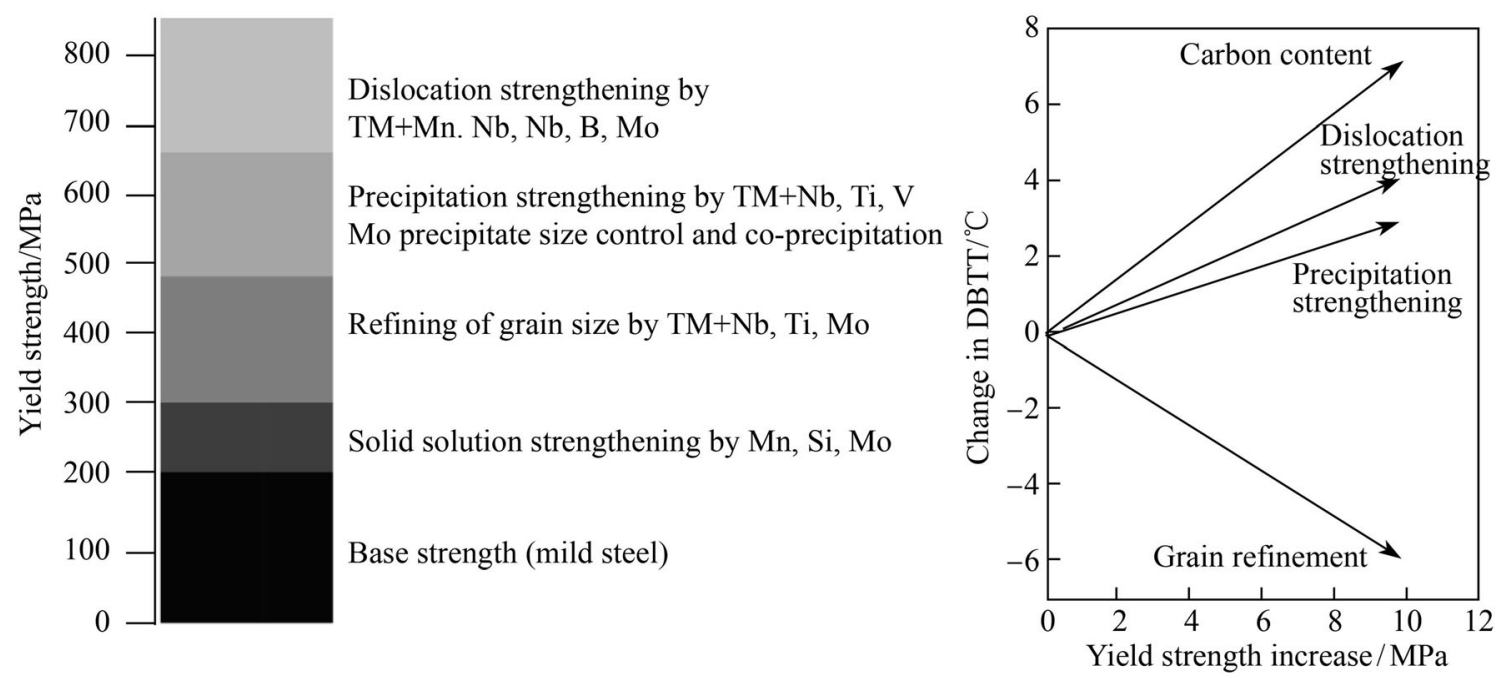

Fig. 1 Strengthening mechanisms in steel and effect on toughness (ductile-to-brittle transition temperature) 
however obvious that the conditions for obtaining the maximum precipitation strengthening are not exactly matching those for dislocation strengthening. Therefore, advanced processing routes have to be established combining both effects to a high degree. By doing so, yield strength can reach in the order of $900 \mathrm{MPa}$ at a carbon content of around $0.05 \%$. Upper-shelf impact energy (Charpy) is typically above $300 \mathrm{~J}$ and DBTT can be as low as $-140{ }^{\circ} \mathrm{C}$. Generally, the more homogeneous the microstructure, the better is the toughness behavior. Avoiding significant scattering of grain sizes is prerequisite for obtaining the best performance in that respect. The presence of the second phase such as pearlite or martensite/ austenite (MA) phase has a clearly detrimental effect on DBTT. Therefore, single phase microstructures are preferred when the best toughness is demanded.

Molybdenum alloying contributes to the production of such advanced steel grades in several ways. The alloyed amount of molybdenum is usually below $0.7 \%$ and more typically in the range of $0.1 \%-0.3 \%$. Despite molybdenum being a carbide former, its alloy range and the low carbon content guarantee full solubility in these steels throughout the process [6]. Thus, the metallurgical effects of molybdenum appear as direct interactions with lattice defects or indirect interactions by way of synergies with other alloying elements. Molybdenum is an atom of significantly larger size than that of iron. It has the tendency of segregating to grain boundaries or binding with other lattice defects such as vacancies or dislocations [7-9]. It also lowers the activity of carbon $[10,11]$, thus slowing down processes that rely on carbon diffusion. Along the processing chain of flat rolled products molybdenum alloying: enhances the solubility of the micro-alloys $\mathrm{Nb}$ and $\mathrm{Ti}$ during slab reheating [10], supports recrystallization delay during austenite conditioning [12], retards precipitation of micro-alloys during austenite conditioning [13], delays phase transformation from fcc to bcc [14], promotes nonpolygonal ferrite formation with high dislocation density [15], controls micro-alloy precipitation in bcc to ultra-fine size and dense particle distribution [16].

\subsection{Strengthening by microstructural refinement and dislocations}

Figure 2 demonstrates the effect of molybdenum in terms of recrystallization delay during austenite rolling compared to a standard C-Mn-Cr steel (see Fig. 2a). The addition of $0.25 \%$ Mo (mass fraction, the same below) produces already clearly pronounced austenite pancaking (see Fig. 2b). This effect is caused by molybdenum's solute drag on the austenite grain boundaries. Furthermore, molybdenum retards dynamic recovery due to its interaction with dislocations. By that, the formation of subgrains acting as nuclei for recrystallization is also retarded [17]. The combination of $0.25 \%$ Mo and $0.04 \% \mathrm{Nb}$ results in even stronger pancaking (see Fig. 2c). Here, solute drag of both elements and additional pinning by $\mathrm{NbC}$ precipitates leads to an earlier and stronger recrystallization delay. Stronger pancaking produces a finer-grained microstructure after the transformation from austenite to ferrite. Besides austenite pancaking, the cooling conditions after hot rolling have a decisive impact on the microstructure of the final product. Molybdenum has also during this processing stage a significant effect on the microstructure. Figure 3 shows the microstructure of two model steels with $\mathrm{Nb}$ - and NbMo-alloying produced at coiling temperatures of $700{ }^{\circ} \mathrm{C}$ (high) and $500{ }^{\circ} \mathrm{C}$ (low). The microstructure after coiling at high temperature is polygonal ferritic. Compared to the $\mathrm{Nb}$ microalloyed base concept, the co-addition of molybdenum produces a finer-grained yet still polygonal ferritic microstructure. At low coiling temperature, the $\mathrm{Nb}$-added steel reveals clearly refined, mostly polygonal ferrite showing a slightly increased amount of low-angle grain boundaries $\left(2^{\circ}<\theta<15^{\circ}\right)$. The addition of molybdenum, however, produces very fine-grained non-polygonal ferrite and a large amount of low-angle grain boundaries. The combination of very fine grain size and pronounced substructure provides an excellent combination of high strength and very low DBTT. The bainitic microstructure comprises a high dislocation density. Figure 4 identifies the individual contributions to strength. Grain refinement is the dominating effect. Low coiling temperature and the addition of molybdenum further promote the strength contribution by grain refinement. Molybdenum enhances the contributions from dislocation density and precipitation at lower coiling temperature whereas the formation of MAphase is promoted at higher coiling temperature. The optimum coiling temperature for all mechanisms acting together appears to be $600{ }^{\circ} \mathrm{C}$.

\subsection{Strengthening by micro-alloy precipitation}

The implementation of precipitation strengthening demands an intermediate cooling regime, providing suitable conditions for the diffusion-based process of forming microalloy carbide particles. Niobium and titanium are most suited for precipitation since their solubility in ferrite is extremely low. Thus, all solute microalloy still being present in austenite after finish rolling precipitates either during or after austenite-to-ferrite transformation, depending on the kinetics. Interphase precipitation occurs quasisimultaneously with the phase transformation as was described in detail for Mo-Ti-alloyed steel by Yen et al. [18]. The development of interphase-precipitated carbides can be associated with the growth of an incoherent ferrite/ austenite interface by the ledge mechanism (see Fig. 5) 


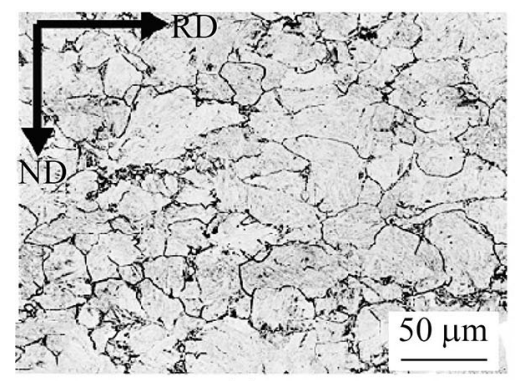

(a)

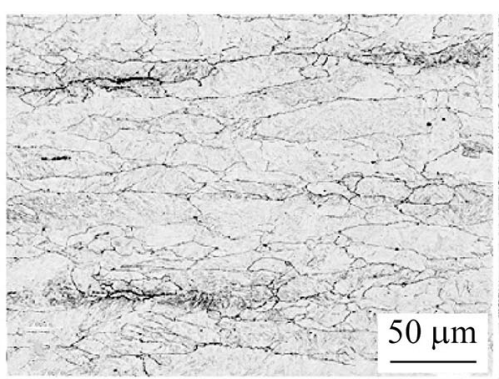

(b)

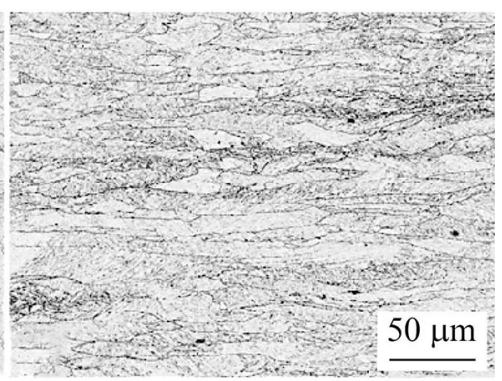

(c)

Fig. 2 Prior austenite grain structures in a C-Mn-Cr steel alloyed with mass fraction a $0 \% \mathrm{Mo}, \mathbf{b} 0.25 \% \mathrm{Mo}, \mathbf{c} 0.25 \% \mathrm{Mo}+0.04 \% \mathrm{Nb}$, rolling reduction of $78 \%$, finish rolling temperature of $900{ }^{\circ} \mathrm{C}$

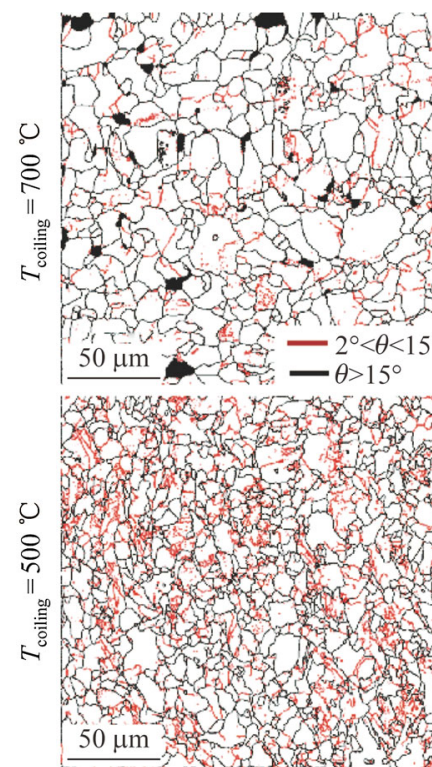

(a) $\mathrm{Nb}$

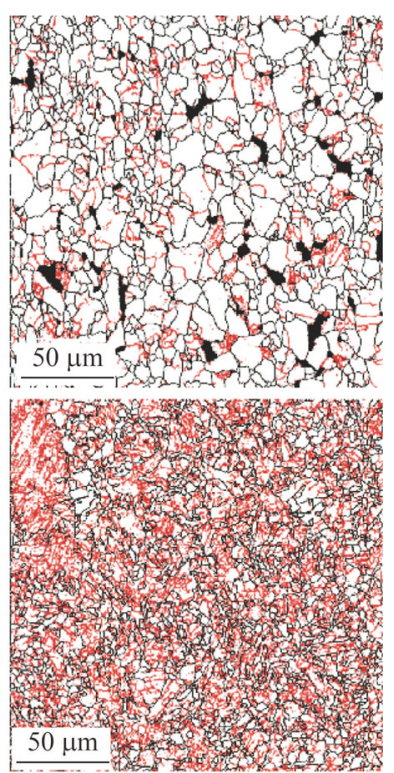

(b) $\mathrm{NbMo}$
Fig. 3 Grain boundary mapping of $0.035 \% \mathrm{Nb}$ and $0.035 \% \mathrm{Nb}-$ $0.2 \% \mathrm{Mo}$ alloyed steel after simulated coiling (base alloy: $0.04 \% \mathrm{C}$ $1.55 \% \mathrm{Mn}-0.2 \% \mathrm{Si}$; black lines = high-angle grain boundaries, red lines $=$ low-angle grain boundaries)
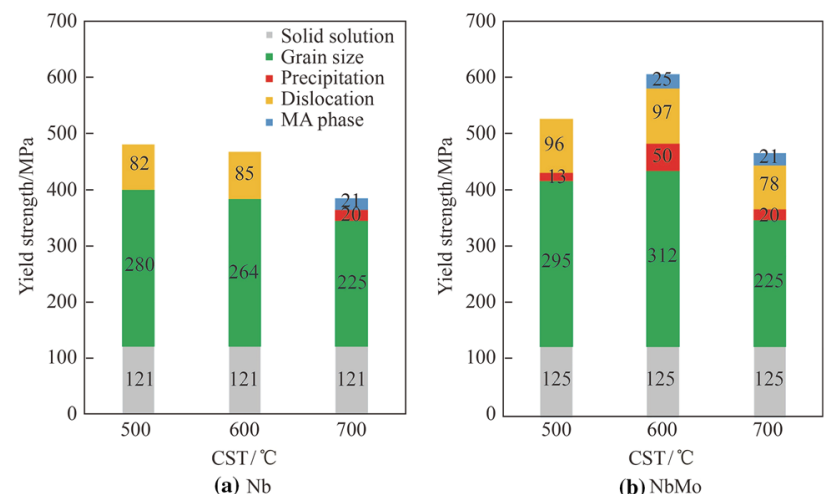

Fig. 4 Contributions to yield strength in function of coiling simulation temperature (CST) for $\mathrm{Nb}$ - and NbMo-alloy making the particles to be aligned in rows. Inter-particle distance along the row and the distance between the rows determine the magnitude of strengthening. The inter-phase precipitation mechanism collapses when the speed of phase transformation is becoming too high, i.e., diffusion of carbon and microalloys is not fast enough to partition to the phase boundary. Molybdenum alloying facilitates interphase precipitation as it retards the transformation (see Fig. 6a) and reduces the phase boundary mobility. The micrographs in Fig. $6 \mathrm{~b}$ clearly show inter-phase precipitation of TiC. The spacing of precipitate rows is the shortest, and the precipitate density along rows is the highest for a simulated coiling temperature of $650{ }^{\circ} \mathrm{C}$.

In the case of low coiling temperature, phase transformation proceeds quickly and is likely finished before precipitation has initiated. Precipitation in this case can only occur spontaneously in the ferritic microstructure. Nucleation sites are provided by dislocation clusters present in this microstructure. In this situation molybdenum assists precipitation by providing a high dislocation density (see Fig. 2). Microalloy carbides have a cubic lattice with considerably larger lattice constant than ferrite. The precipitates nucleate with a Baker-Nutting orientation relationship $[100]_{\mathrm{MC}} / /[110]_{\alpha-\mathrm{Fe}},(100)_{\mathrm{MC}} / /(100)_{\alpha-\mathrm{Fe}}$ reducing the lattice misfit to $2.2 \%, 6.8 \%$ and $10.1 \%$ for $\mathrm{VC}$, TiC and $\mathrm{NbC}$, respectively. The formation enthalpy for the carbides is $-44.2,-78.1$ and $-47.5 \mathrm{~kJ} / \mathrm{mol}$ for $\mathrm{VC}, \mathrm{TiC}$ and $\mathrm{NbC}$, respectively. Considering the combination of solubility in ferrite, lattice mismatch and formation enthalpy, it appears that titanium carbide should be the most efficient for precipitation strengthening. Molybdenum has a formation enthalpy of $+16.5 \mathrm{~kJ} / \mathrm{mol}$. Thus, neither the precipitation of molybdenum as such nor the partial replacement of $\mathrm{Ti}$ by Mo in $\mathrm{TiC}$ is energetically favorable. However, the formation of a (Ti, Mo) mixed carbide in the early formation stage reduces the interfacial strain energy 


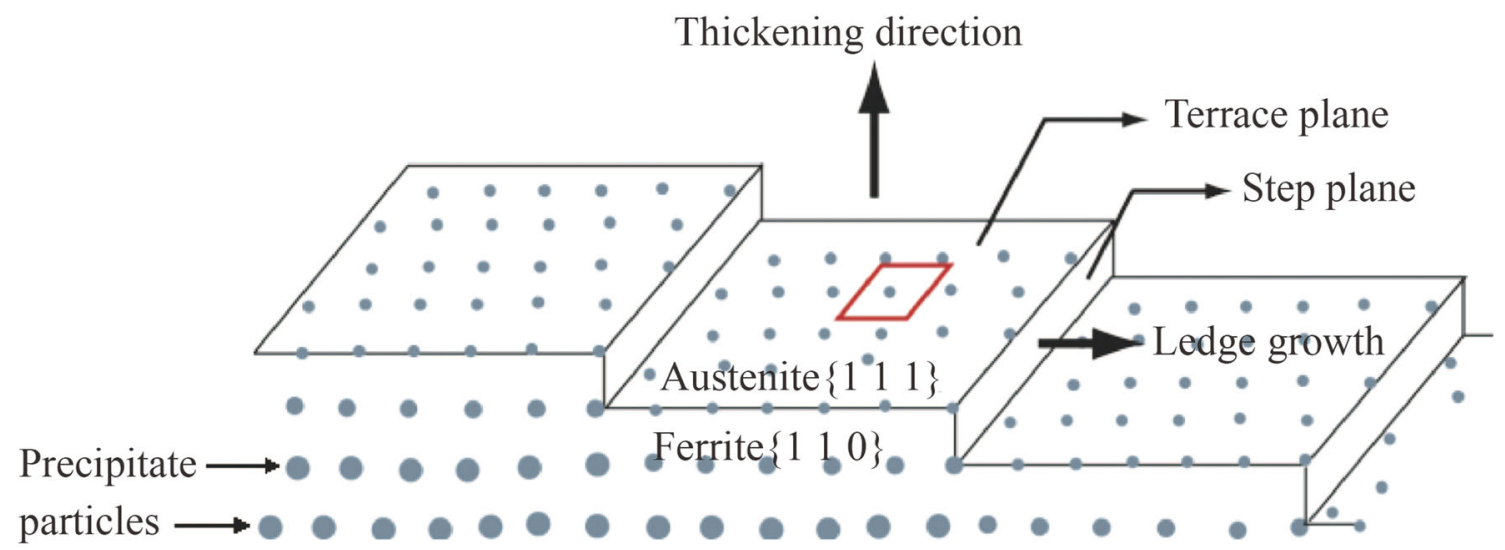

Fig. 5 Interphase precipitation by ledge mechanism during slow transformation from austenite to ferrite

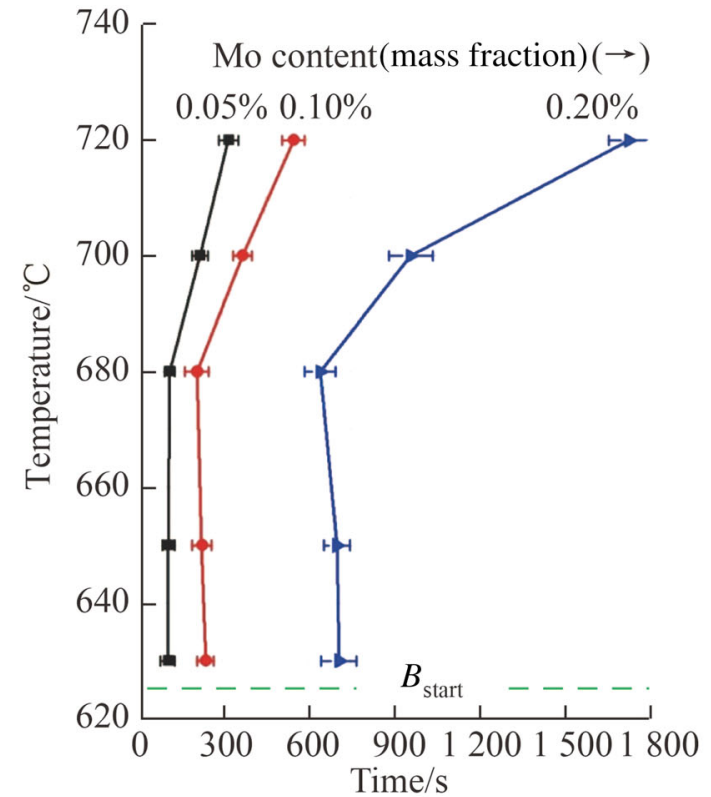

(a)

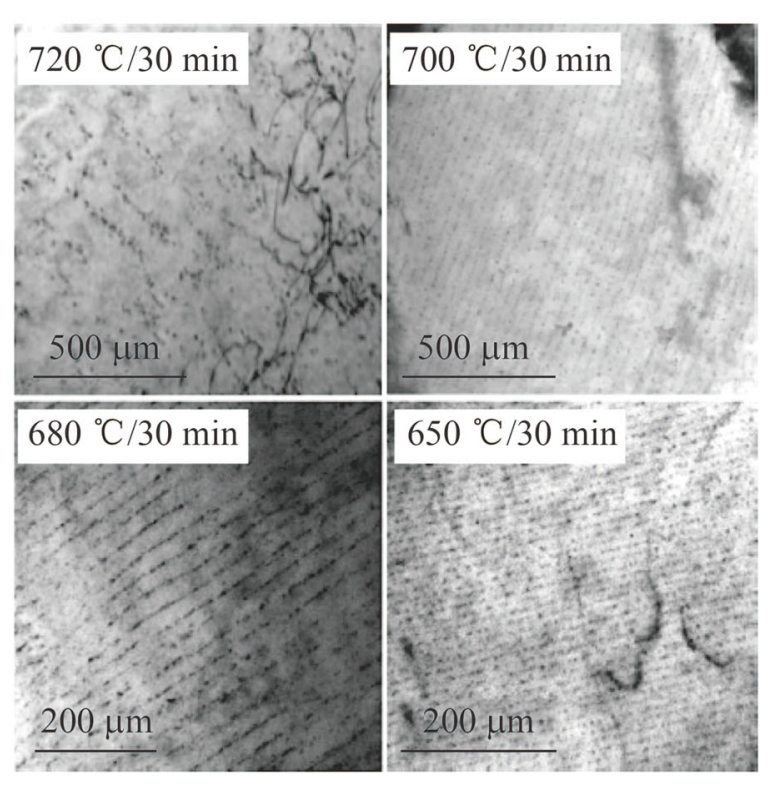

(b)

Fig. 6 Metallurgical effects after finishing of hot rolling enabling steel strengthening by interphase precipitation a delay effect of molybdenum on the austenite-to-ferrite transformation, $\mathbf{b}$ influences of coiling temperature on the precipitate particle distribution

between precipitate and ferrite matrix. Molybdenum can thus facilitate particle nucleation.

Figure 7 compares the influence of coiling temperature on three alloy concepts. Besides the mass fraction $0.04 \% \mathrm{Nb}$ and $0.04 \% \mathrm{Nb}-0.2 \%$ Mo alloys already discussed before, a $0.09 \% \mathrm{Ti}-0.2 \%$ Mo alloy with the same base composition is included here. All three alloy concepts reveal their maximum strength at a coiling temperature of $600{ }^{\circ} \mathrm{C}$ (see Fig. 7a). Clearly, the TiMo alloy shows the highest strength level at any coiling temperature. Although the NbMo alloy has the smallest average grain size (see Fig. 7b), the larger strength in the TiMo is originating from precipitation. At a given coiling temperature, the various strengthening mechanisms are contributing to the total strength with different magnitudes. The best compromise is achieved in the current model alloys and thermo-mechanical treatment conditions at a simulated coiling temperature of $600{ }^{\circ} \mathrm{C}$. The $\mathrm{Nb}$-alloy shows only a small strengthening contribution by precipitation. The addition of molybdenum in the NbMo-alloy significantly promotes precipitation. The TiMo-alloy contains a higher amount of microalloy $(0.09 \% \mathrm{Ti}$, mass fraction) than the NbMo-alloy $(0.04 \% \mathrm{Nb}$, mass fraction). Therefore, the number of precipitates is larger leading to higher strengthening. The kinetics of $\mathrm{Ti}$ precipitation is also faster than that of $\mathrm{Nb}$. Thus, precipitation can be considered being more complete in the TiMoalloy within the isothermal holding period of $90 \mathrm{~min}$ applied here. 


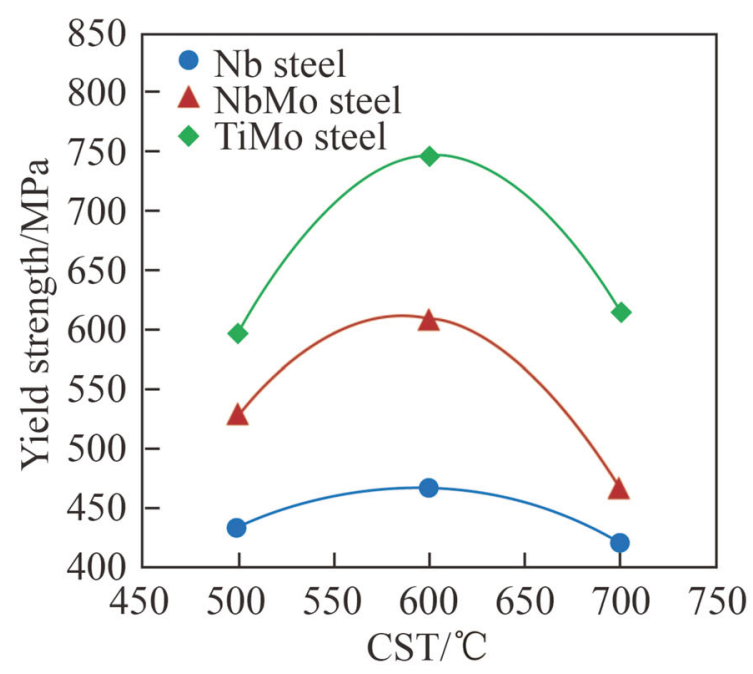

(a)

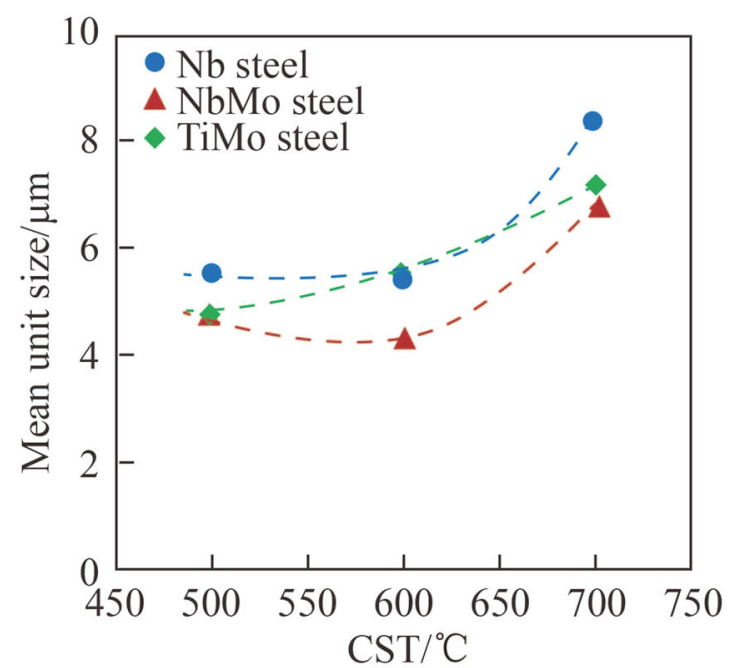

(b)

Fig. 7 Dependence of a yield strength and $\mathbf{b}$ grain size on CST and alloy concept

\subsection{Two-step processing with secondary heat treatment}

In real production of plate or strip steel, the material is continuously cooling from the CST, be it at slow rate. The actual slow-cooling rate is less for a coil than for a plate. Accordingly, the time period that the steel resides in the temperature range favorable to precipitation is shorter for plate than for coiled strip products. Therefore, it is quite difficult to obtain a large contribution of precipitation strengthening in plate products, especially when simultaneously fine grain size demands a low. This conflict can be solved by process modification. In the first step, bainitic microstructure with fine grain size and high dislocation density is produced by targeting a low cooling-stop temperature. In the second step, the fine-grained bainitic steel is re-heated to a temperature allowing efficient precipitation [19]. It is important in this process sequence that the initially produced bainitic structure with high dislocation density is not being removed by recovery or recrystallization during the subsequent annealing process. In this respect molybdenum acts as a stabilizing element retaining the pronounced sub-structure as well as high dislocation density generated in the initial process step. Figure 8 demonstrates this effect for the same TiMo-alloy as discussed before. In the initial process step the alloy is rolled and subsequently accelerated cooled $(15 \mathrm{~K} / \mathrm{s})$ to $650{ }^{\circ} \mathrm{C}$ followed by continuous slow cooling $(1 \mathrm{~K} / \mathrm{s})$ to room temperature. This process results in a bainitic microstructure with high dislocation density (see Figs. 8a, c) containing a share of MA-phase. The second processing step is fast induction heating to a peak temperature of $710{ }^{\circ} \mathrm{C}$ followed by slow cooling $(1 \mathrm{~K} / \mathrm{s})$ back to room temperature. The induction heat treatment (HT) decomposes the MA-phase, yet neither reduces the grain boundary density (see Fig. 8b) nor the dislocation density (see Fig. 8d). However, the precipitate density is significantly increased by the induction heat treatment. The analysis of mechanisms contributing to strength (see Fig. 8e) indicates no precipitation strengthening after the initial process step. The induction heat treatment generates a strength gain of around $130 \mathrm{MPa}$ by precipitation. The strength contribution by MA-phase present after the initial process stage disappears after heat treatment but is balanced by more contribution from grain refinement. This is beneficial to toughness and partially compensates for the detrimental effect caused by precipitation.

Compared to a strip product coiled under optimized conditions (see Fig. 7a), the strength of the heat-treated plate with identical alloy concept (see Fig. 8e) appears still inferior. The reason is the shorter residence of the steel in the temperature range favorable to precipitation. By decoupling the two processing stages it is possible to perform heat treatment of longer duration. That possibility is demonstrated using a $0.05 \% \mathrm{C}-1.7 \% \mathrm{Mn}-0.18 \% \mathrm{Cr}-0.08 \% \mathrm{Nb}$ (mass fraction) model alloy with Mo additions ranging from 0 to $0.3 \%$ [20]. The steels are fast cooled after rolling to a cooling-stop temperature of $450{ }^{\circ} \mathrm{C}$ and held for $10 \mathrm{~min}$ followed by air-cooling to room temperature. In the second stage, the steels are heated to $600{ }^{\circ} \mathrm{C}$ and held for up to $8 \mathrm{~h}$. It is found that the presence of granular bainite in the microstructure is necessary for efficient precipitation. Granular bainite contains a high dislocation density and the dislocation line is the most advantageous nucleation site for heterogeneous precipitation of $\mathrm{Nb}$ carbides in a bcc matrix. Increasing molybdenum content enhances the share of 

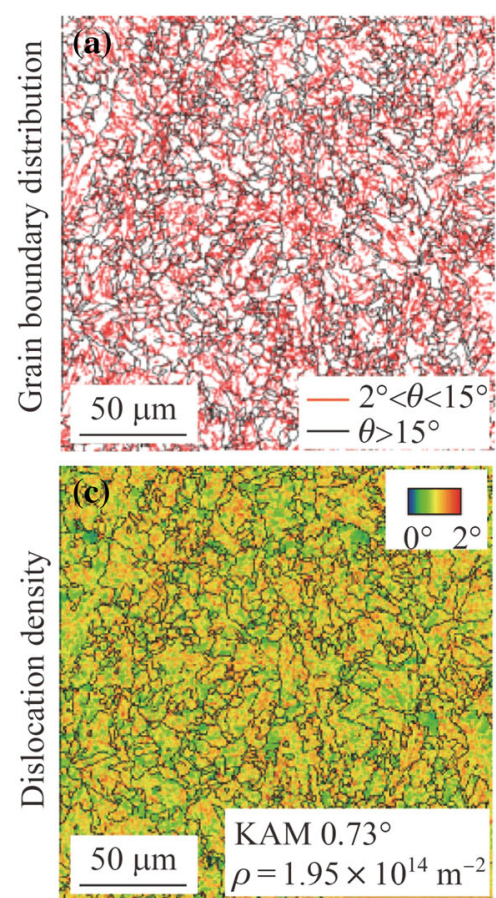

CST: $650{ }^{\circ} \mathrm{C}$
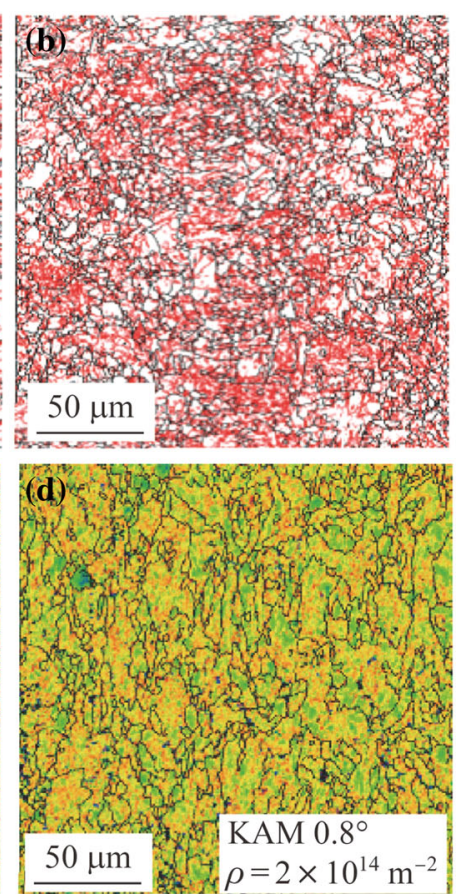

CST: $650{ }^{\circ} \mathrm{C}+\mathrm{HT}: 710^{\circ} \mathrm{C}$

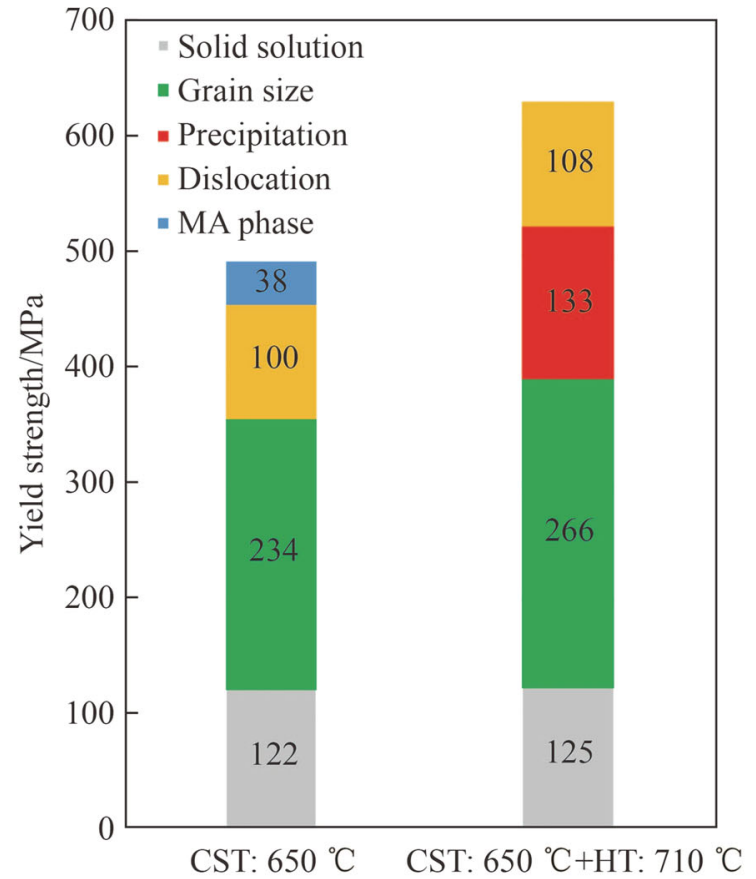

(e)

Fig. 8 Grain boundary distribution before a and after $\mathbf{b}$ heat treatment (HT) in a TiMo-alloy, dislocation density before $\mathbf{c}$ and after $\mathbf{d}$ heat treatment in a TiMo-alloy, e contributions to yield strength before and after heat treatment

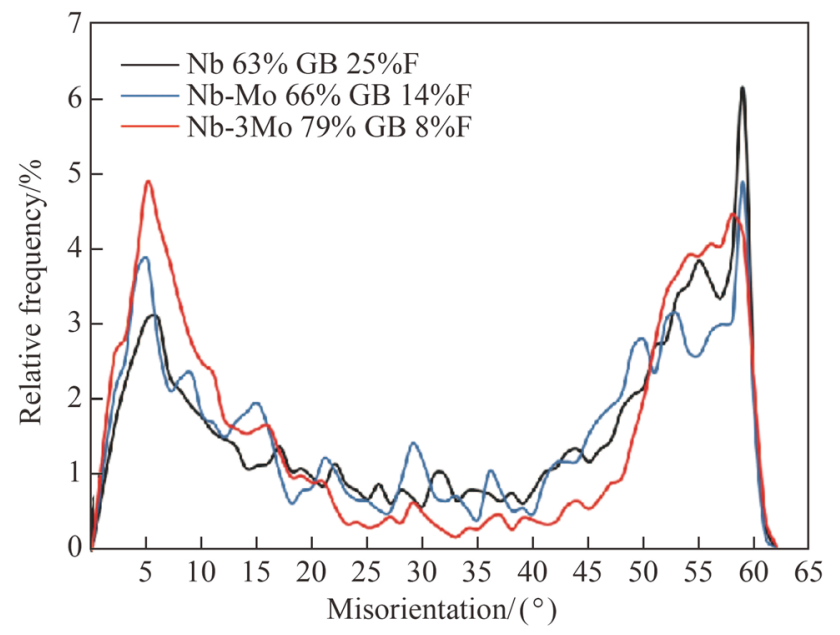

Fig. 9 Density distributions of grain boundary misorientation angle and amount of granular bainite (GB) and ferrite $(\mathrm{F})$ in $0.05 \% \mathrm{C}$ $0.2 \% \mathrm{Si}-1.7 \% \mathrm{Mn}-0.18 \% \mathrm{Cr}-0.016 \% \mathrm{Ti}-0.08 \% \mathrm{Nb}$ (mass fraction) alloys added with $0.1 \%$ and $0.3 \% \mathrm{Mo}$ (mass fraction) $\left(\mathrm{CST}=450{ }^{\circ} \mathrm{C}\right.$ )

granular bainite (see Fig. 9). The heat treatment at $600{ }^{\circ} \mathrm{C}$ results in a significant yield strength increase after a duration of $1 \mathrm{~h}$ (see Table 1). The precipitation effect is the largest for the $\mathrm{Nb}-0.1 \% \mathrm{Mo}$ (mass fraction) alloy gaining $140 \mathrm{MPa}$ in yield strength. After $8 \mathrm{~h}$ heat treatment, overageing leads to a small loss of strength. The $\mathrm{Nb}-0.3 \% \mathrm{Mo}$ (mass traction) alloy has the highest overall strength since it contains the largest share of granular bainite. All three alloys quite well retain their strength even after $8 \mathrm{~h}$ exposure to high temperature. Elongation improves significantly which is a favorable result considering the achieved strength increase (see Table 1).

The practical implementation of a two-step process with initial fast cooling to obtain non-polygonal ferritic microstructure and secondary heat treatment to promote precipitation strengthening can be realized in several different ways (see Fig. 10). Using tempering furnaces for plate products or batch annealing (BA) for coiled products requires long annealing periods at temperatures below $A_{\mathrm{c} 1}$. For lower gages, online inductive heating has been already implemented by Japanese steelmaker JFE and is known under the term "heating online process" (HOP). In this quick heating process, a relatively high peak temperature allows achieving faster precipitation. Modern technologies such as compact strip processing (CSP), endless strip production (ESP) or ultra-thin cast strip (UCS) processing allow producing thin-gaged hot rolled strip. These products can be treated in the same way as traditional cold rolled steel using continuous annealing (CAL) or hot-dip galvanizing (HDG) lines. Typically, the residence time on peak annealing temperature is $60-120 \mathrm{~s}$. Annealing temperatures closer to $A_{\mathrm{c} 1}$ will result in more complete precipitation. 


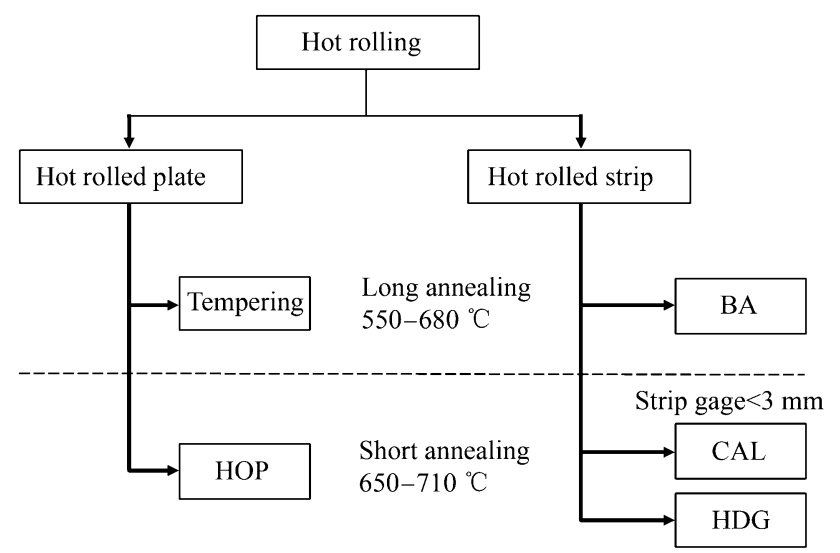

Fig. 10 Possibilities of two-step processing for combining microstructural strengthening and precipitation strengthening in hot rolled products

Table 1 Effects of heat treatment at $600{ }^{\circ} \mathrm{C}$ on mechanical properties of $\quad 0.05 \% \mathrm{C}-0.2 \% \mathrm{Si}-1.7 \% \mathrm{Mn}-0.18 \% \mathrm{Cr}-0.016 \% \mathrm{Ti}-0.08 \% \mathrm{Nb}$ (mass fraction) alloys added with $0.1 \%$ and $0.3 \% \mathrm{Mo}$ (mass fraction) $\left(\mathrm{CST}=450^{\circ} \mathrm{C}\right)$

\begin{tabular}{|c|c|c|c|c|c|c|c|c|c|}
\hline \multirow{2}{*}{$\begin{array}{l}\text { Tempering } \\
\text { time/h }\end{array}$} & \multicolumn{3}{|l|}{$\mathrm{Nb}$} & \multicolumn{3}{|c|}{ Nb-Mo } & \multicolumn{3}{|c|}{$\mathrm{Nb}-3 \mathrm{Mo}$} \\
\hline & $\begin{array}{l}Y_{\mathrm{S}} / \\
\mathrm{MPa}\end{array}$ & $\begin{array}{l}T_{\mathrm{S}} / \\
\mathrm{MPa}\end{array}$ & $\begin{array}{l}E_{1} / \\
\%\end{array}$ & $\begin{array}{l}Y_{\mathrm{S}} / \\
\mathrm{MPa}\end{array}$ & $\begin{array}{l}T_{\mathrm{S}} / \\
\mathrm{MPa}\end{array}$ & $\begin{array}{l}E_{1} / \\
\%\end{array}$ & $\begin{array}{l}Y_{\mathrm{S}} / \\
\mathrm{MPa}\end{array}$ & $\begin{array}{l}T_{\mathrm{S}} / \\
\mathrm{MPa}\end{array}$ & $\begin{array}{l}E_{1} / \\
\%\end{array}$ \\
\hline 0 & 512 & 630 & 22 & 479 & 683 & 21 & 575 & 679 & 19 \\
\hline 1 & 594 & 652 & 29 & 619 & 678 & 27 & 672 & 718 & 27 \\
\hline 8 & 586 & 638 & 30 & 605 & 655 & 27 & 651 & 702 & 27 \\
\hline
\end{tabular}

Note: $Y_{\mathrm{S}}$ - Yield strength, $T_{\mathrm{S}}$ - Tensile strength, $E_{1}$ - Elongation

\subsection{Application examples of high-performance HSLA steels}

China has been the first country installing large-scale pipeline systems applying X80 grade pipe steel [24]. This steel is mostly produced as hot-rolled strip for spiral welded pipe. However, hot-rolled plate is used for longitudinal welded pipe when particularly heavy wall gage is needed. Due to toughness requirements, a carbon content of $0.04 \%-$ $0.06 \%$ and a homogeneous, fine-grained acicular ferritic microstructure is preferred [25]. Alloy concepts using $0.07 \%-0.1 \% \mathrm{Nb}$ and $0.2 \%-0.3 \%$ Mo have been established as robust solution for hot-rolled strip production. Severe austenite pancaking followed by accelerated cooling to a low coiling temperature are key process characteristics. Initially, plate steel alloy designs did not use Mo-alloying due to the more efficient cooling after finish rolling. More recent modifications of plate steel X80 alloys, however, considered Mo additions of around $0.2 \%$. This modification provides a better process robustness and also improves toughness properties especially when heavier gages of around $30 \mathrm{~mm}$ have to be produced. Recent pipe steel developments are targeting the strength levels of X90 and X100. A cost-effective approach to X-100 with a minimum of $6 \%$ uniform elongation to meet strain-based design requirements is using $0.08 \% \mathrm{Nb}$ and $0.25 \%$ Mo base chemistry produced into a dual-phase microstructure of ferrite and a carbon rich second phase [26]. Such multiphase processing requires holding in the inter-critical temperature regime before quenching and thus needs the superior capabilities of a modern hot rolling mill.

Light-weighting of frame and chassis structures for commercial vehicles including trailers has been a major driving force for developing hot strip grades with minimum yield strength of $700 \mathrm{MPa}$ in the gage range of $5-10 \mathrm{~mm}$ $[1,2]$. Recent developments in China introduced truck frame steel grades with $600 \mathrm{MPa}$ yield strength and higher. The alloy design is based on low carbon content and $\mathrm{Nb}-\mathrm{Ti}$ dual microalloying [27]. With this concept either polygonal ferritic or bainitic microstructure with precipitation strengthening can be produced depending on the run-out table conditions in the hot-strip mill. The presence of pearlite or other hard phases in the microstructure is rather avoided as these have a negative impact on the bendability. Furthermore, such hard particles also lead to edge damage after mechanical cutting and cause increased wear on cutting tools. Pearlite-free steels intrinsically feature good toughness and fatigue resistance due to fine grain size and low carbon content. For reaching $700 \mathrm{MPa}$ yield strength most concepts are based on $0.06 \% \mathrm{C}-1.8 \% \mathrm{Mn}-0.06 \% \mathrm{Nb}-$ Ti-Mo alloying. This concept exhibits a remarkable robustness against temperature variations on the run-out table of the hot-strip mill [1]. The resulting narrow scattering of strength is beneficial to forming operations in manufacturing, especially with respect to compensating spring-back occurring during forming of high strength steel. Good weldability is a result of reduced CE and particularly a low absolute carbon content. The CE (IIW) is typically in the range of $0.35-0.45$ so that harden ability is rather low. The carbon content being typically clearly below 0.1 reduces peak hardness in particular, thus minimizing the risk of cold cracking.

Besides strength, many applications require other properties such as resistance against weathering or increased temperature. Substitution of traditional SPA-H steel $(\min$ (yield strength $)=355 \mathrm{MPa})$ by higher strength steel (yield strength $>550 \mathrm{MPa}$ ) enables weight reduction of $15 \%-20 \%$ in the construction of shipping containers or truck cargo boxes resulting in significantly lower fuel consumption. The reduced gage of such containers requires, however, a relatively better weathering resistance to guarantee sufficient lifetime. Typical alloying elements in weathering steels are $\mathrm{Cr}, \mathrm{Cu}$ and $\mathrm{Ni}$. Molybdenum additionally contributes to weathering resistance and simultaneously increases strength. A practical alloy 
concept for $700 \mathrm{MPa}$ weathering steel uses around $0.2 \%$ Mo added to a low-carbon $\mathrm{Cr}-\mathrm{Cu}-\mathrm{Ni}$-Nb-Ti base alloy. The microstructure of finished steel ideally consists of acicular ferrite and granular bainite, while keeping the share of MA-phase on a low level for guaranteeing high toughness and good cold bending properties. Other weather resistant steel applications for bridges or transmission line towers requiring yield strength in the range of $460-550 \mathrm{MPa}$ are produced as heavy plate or angles. Molybdenum addition in the range of $0.2 \%-0.4 \%$ to these products consisting of a $\mathrm{Cr}-\mathrm{Cu}-\mathrm{Ni}-\mathrm{Nb}$ base alloy showed appreciable improvement of weathering resistance [28].

Engineering codes for the construction of high-rise buildings sometimes demand fire resistant steel to be used in vertical columns [29]. Such steels are intended to resist accelerated creep, or thermally activated deformation when exposed to high temperature for a relatively short time. It has been shown that additions $0.5 \% \mathrm{Mo}$ and $0.02 \% \mathrm{Nb}$ to a standard grade 50 steel increased the elevated temperature strength in a synergetic way. Molybdenum by itself reduces softening and enhances creep resistance at elevated temperature. It also prevents niobium precipitates from coarsening and thus helps maintaining that strengthening mechanism during elevated temperature exposure [30].

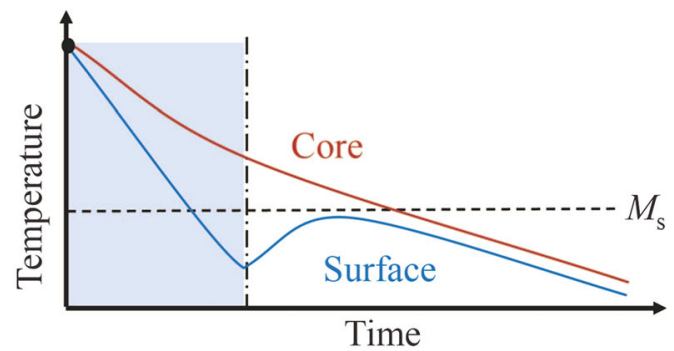

(a) Direct quenching (DQ)

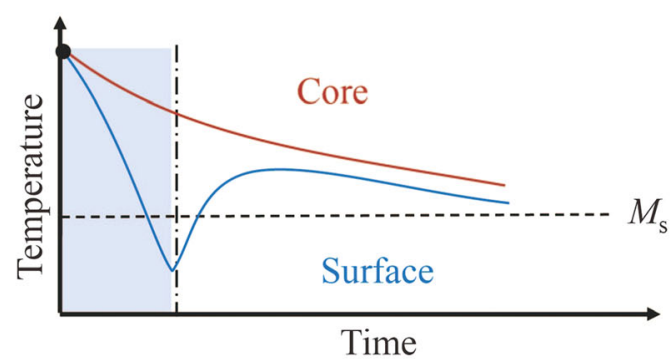

(c) Direct quenching \& self tempering (DQST)

\section{Alloy concepts and processing routes for martensitic steels}

Increasingly many applications in manufacturing of machinery, agricultural, hoisting or transportation equipment as well as vehicle structures require material strength clearly above $800 \mathrm{MPa}$ [21-23]. Such a strength level is difficult to achieve with the low-carbon HSLA steel approach described in Sect. 2 of this paper. Martensitic steel can readily fulfil demands for ultra-high strength and hardness. However, unless it is sufficiently tempered, martensite has lower ductility and toughness than ferritic or bainitic steels. When the strength is passing the threshold of roughly $1000 \mathrm{MPa}$, steels also become increasingly sensitive to hydrogen embrittlement [31]. The presence of diffusible hydrogen in martensitic steel can severely lower fracture toughness or cause so-called "delayed cracking" which unexpectedly destroys an initially sound component [32]. Such critical issues require metallurgical optimization, which is related to the alloy concept and processing.

\subsection{Process variants for producing martensitic steels}

The lack of formability in martensitic steel has been elegantly solved by the automotive industry using a process called "press hardening" or "hot stamping" (see Fig. 11). Forming is done in the hot, thus, austenitic state and subsequent quenching by the water-cooled stamping die assures the transformation to martensite. The paint-baking

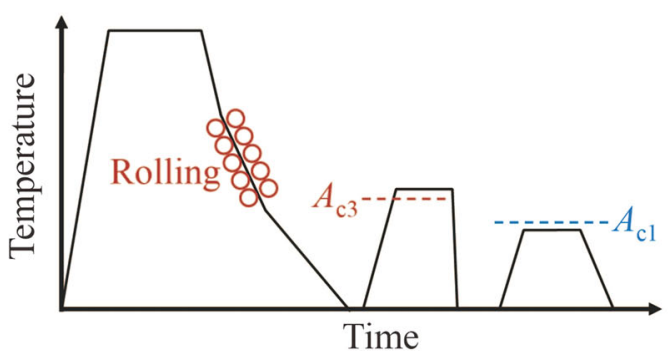

(b) Reheat quenching (\& tempering)

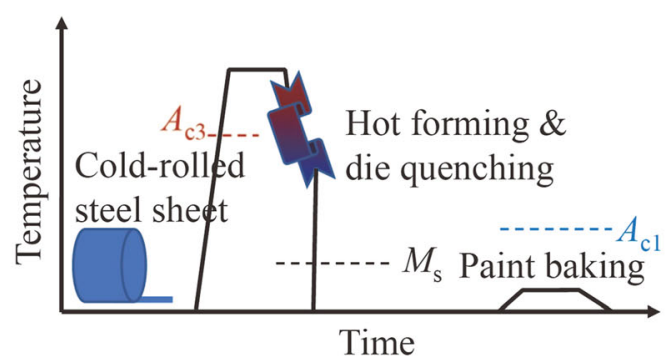

(d) Press hardening process

Fig. 11 Production principles for producing martensitic or tempered martensitic steel $\left(M_{\mathrm{s}}\right.$ : martensite-start temperature, $A_{\mathrm{c} 3}$ : end of austenite transformation, $A_{\mathrm{c} 1}$ : start of austenite transformation) 
process $\left(170{ }^{\circ} \mathrm{C}\right.$ for $\left.20 \mathrm{~min}\right)$ at the end of car body manufacturing acts as a low-temperature tempering treatment to the press hardened components. The production of martensitic hot-rolled strip and plate is nowadays preferably practiced via direct quenching (DQ) from the rolling heat (see Fig. 11). This procedure makes the traditional reaustenitizing and quenching process obsolete, thus, reducing energy consumption, simplifying in-plant logistics and largely enhancing production capacity. The objective of DQ is to produce microstructures consisting predominantly of martensite and/or bainite by utilizing the highest possible cooling rates. Modern cooling facilities can easily apply cooling rates of $100 \mathrm{~K} / \mathrm{s}$. However, such high cooling rates apply only to thin-gauge plates and to the surface-near area of heavy gaged plates. The attainable cooling rate at the plate core is substantially lower and decreases with increasing plate thickness. Subsequent tempering is required for adjusting an adequate balance of tensile and toughness properties. By applying very short and intensive cooling, which is interrupted before the plate center is cooled below martensite-start temperature, the remaining heat will provide an in-line tempering effect. This process is termed quenching and self-tempering $(\mathrm{QST})$. In the most

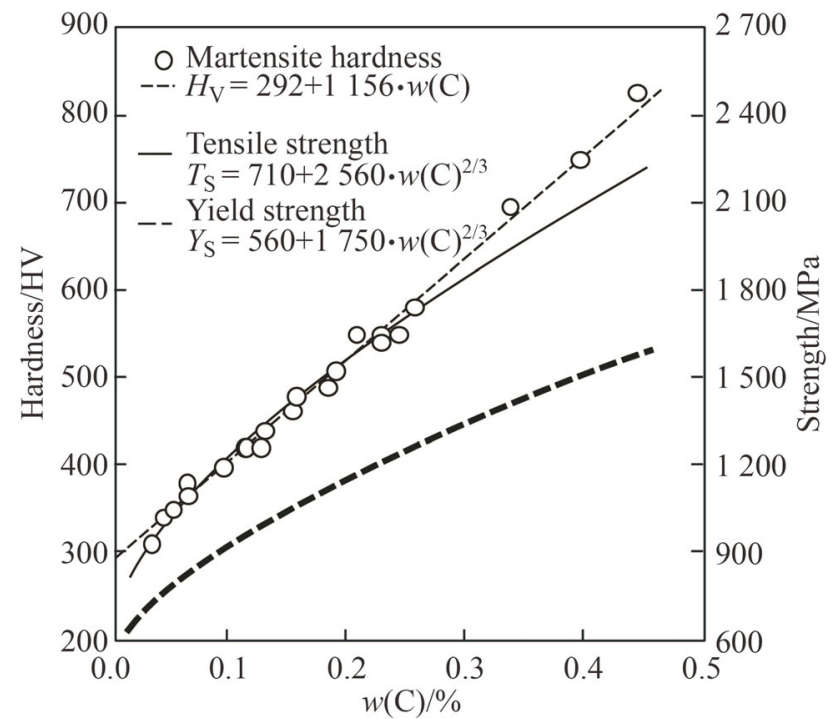

(a)

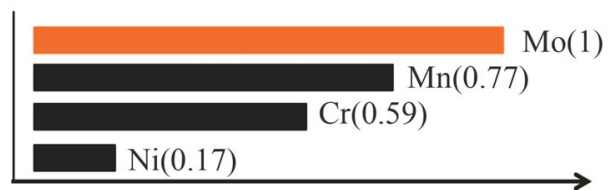

Hardenable gage (rel. scale)

(b)

Fig. 12 Effects of alloying elements in martensitic steel a influences of carbon content on measured hardness (HV0.5) and comparison to calculated strength [34] in unalloyed carbon-manganese steel in asquenched condition, b relative effect of alloying elements on hardening depth favorable arrangement, the cooling facility is positioned directly behind the last stand of the rolling mill. Accordingly, the finish rolling temperature equals the cooling start temperature. It is also acceptable having a short transfer time (up to $30 \mathrm{~s}$ ) without causing a detrimental effect on the mechanical properties after DQ [33].

\subsection{Molybdenum alloying effects in martensitic steels}

Considering alloy concepts, carbon is the dominating element providing strength to martensite (see Fig. 12a). A carbon content of only $0.08 \%$ results in tensile strength of around $1100 \mathrm{MPa}$ and yield strength of over $900 \mathrm{MPa}$. The highest tensile strength applied recently in car body components approaches $2000 \mathrm{MPa}$. Such martensitic steel is alloyed with $0.34 \% \mathrm{C}$. Alloying elements boosting hardenability need to be used for achieving full martensitic strength, especially in products of heavier gage. For the same weight percentage added, molybdenum is the most powerful hardenability element compared to other typical alloys such as manganese, chromium, or nickel according to the ratio shown in Fig. 12b [35]. Micro-alloying of boron increases hardenability very effectively. Simple lowcost martensitic steels rely on a Mn-B alloy concept. However, this basic alloy concept cannot fulfil advanced requirements with regard to toughness and delayed cracking resistance.

Using molybdenum as alloying element to martensitic steel not only offers superior harden ability but brings about additional benefits such as microstructural refinement, tempering resistance, delayed cracking resistance, synergy effects with other alloying elements.

The martensitic microstructure develops within the prior austenite grains present before quenching [36]. Therefore, austenite conditioning has a direct influence on the final martensite properties such as strength and toughness $[37,38]$. It was already demonstrated in Fig. 2 that molybdenum significantly contributed to austenite pancaking during finishing hot rolling. This effect is even stronger in combination with niobium microalloying. The pancaked microstructure is quenched into martensite directly after finish rolling when applying the DQ process. Accordingly, the martensitic sub-structure develops within pancaked prior austenite grains. On the contrary, for reheat quenching processes, the pancaked austenite transforms into a typically ferritic-pearlitic microstructure by conventional cooling. The latter is clearly finer in a $\mathrm{Mo}-\mathrm{Nb}$ alloy as compared to a Nb-only alloy [38]. The finer ferritepearlite microstructure provides a faster re-austenitizing kinetics, thus accelerating the reheating process. Solute drag by molybdenum and precipitate pinning in niobium is co-alloyed concepts control the austenite grain size and 


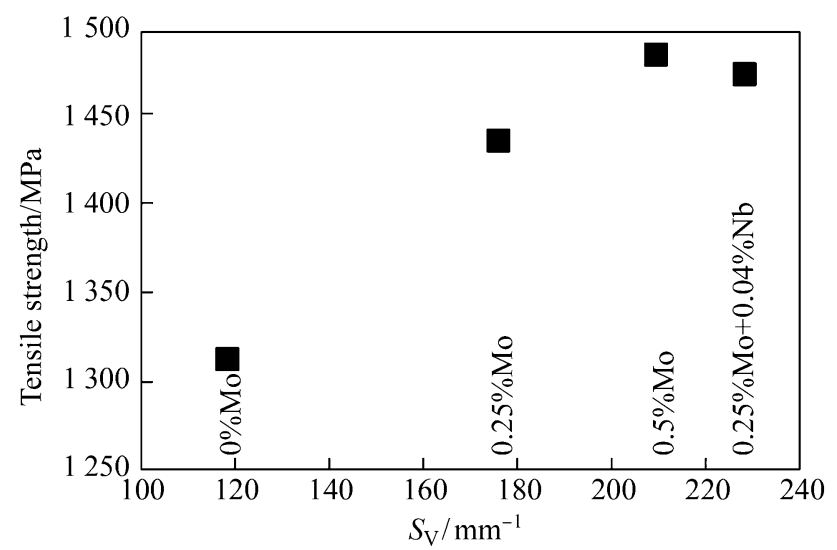

(a)

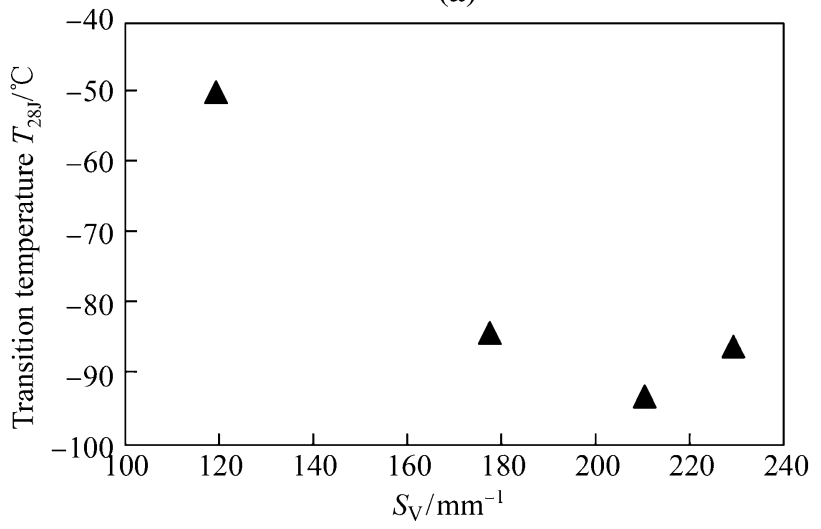

(b)

Fig. 13 Influence of molybdenum and molybdenum-niobium synergy on strength and toughness of directly quenched $0.16 \% \mathrm{C}-\mathrm{Mn}-\mathrm{Cr}-$ $\mathrm{Ni}$ base alloy measured in transverse direction (FRT: $900{ }^{\circ} \mathrm{C}$ ) (intensity of austenite pancaking expressed as $S_{\mathrm{v}}=0.429(1 /$ $\left.\left.d_{\mathrm{RD}}\right)+0.571\left(1 / d_{\mathrm{TD}}\right)+\left(1 / d_{\mathrm{ND}}\right)\right)$

guarantee quenching into martensite from a more refined prior austenitic microstructure. It was shown that the martensite packet correlated with the austenite pancake thickness size for DQ steels [38]. Therefore, better strength and toughness properties can be expected with increasing molybdenum alloy content due to stronger austenite pancaking. Figure 13 demonstrates this effect using the ratio of grain boundary area to volume being a measure for the degree of austenite pancaking. With increasing molybdenum content in the range of $0-0.5 \%$ austenite pancaking becomes more pronounced and the tensile strength increases by almost $180 \mathrm{MPa}$. Simultaneously, the transition temperature $\left(T_{28 \mathrm{~J}}\right)$ decreases from $-50{ }^{\circ} \mathrm{C}$ in the Mofree steel to below $-90{ }^{\circ} \mathrm{C}$ in the $0.5 \% \mathrm{Mo}$ added steel. The combination of $0.25 \% \mathrm{Mo}$ and $0.04 \% \mathrm{Nb}$ results in even stronger austenite pancaking ( $S_{\mathrm{V}}$ parameter), yet the improvement of properties appears to saturate on high level. Applying a high-temperature tempering treatment $\left(600{ }^{\circ} \mathrm{C}\right.$ for $\left.30 \mathrm{~min}\right)$ to the same alloys necessarily leads to a gain of $40 \%-60 \%$ in elongation on the expense of

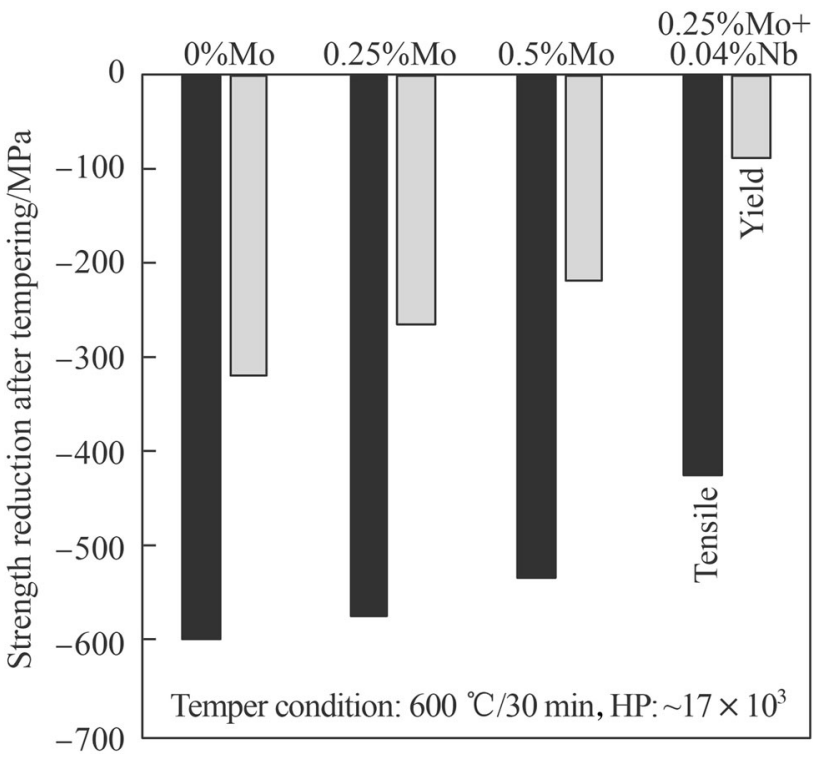

Fig. 14 Reduction of yield and tensile strength after tempering treatment of directly quenched $0.16 \% \mathrm{C}-\mathrm{Mn}-\mathrm{Cr}-\mathrm{Ni}$ base alloy (HP: Hollomon-Jaffe parameter)

strength (see Fig. 14). The temper-induced strength loss is particularly large in the Mo-free alloy. Increasing molybdenum addition reduces the strength loss. Particular high tempering resistance is found for the $0.25 \% \mathrm{Mo}-0.04 \% \mathrm{Nb}$ alloyed variant. It appears that niobium precipitates formed during the tempering treatment deliver around $180 \mathrm{MPa}$ additional yield strength as compared to the $0.25 \% \mathrm{Mo}$ alloy. Regarding the tensile strength the same effect applies but is with about $150 \mathrm{MPa}$ somewhat smaller.

The sensitivity to hydrogen embrittlement is a consequence of three conditions acting together: microstructure, diffusible hydrogen and stress. Diffusible hydrogen present in a martensitic steel can originate from different sources such as steel making, intermediate treatments, welding or corrosion occurring during operational conditions. Pronounced hydrogen embrittlement is observed when the amount of diffusible hydrogen in the steel is high. In this case hydrogen aggregates at prior austenite grain boundaries present in the martensitic microstructure. Hydrogen lowers grain boundary cohesion so that in severe cases the material fails far below the actual yield strength with practically zero ductility. The resulting fracture pattern is showing intergranular cracking along the prior austenite grain boundaries. In less severe case of hydrogen embrittlement, the fracture pattern changes to the quasi-cleavage type. If the diffusible hydrogen content remains below a critical threshold value, ductile fracture occurs showing the typical dimple type pattern. The challenge towards alloy and process design is to appropriately modify the steel so that it can sustain the typical amount of hydrogen being picked up by the material during all phases of production 
and over the component service life. The microstructural cornerstones of such a modification are [38]: (i) Refinement of the prior austenite grain size before final quenching to lower the hydrogen concentration per unit grain boundary area. (ii) Introduction of hydrogen trapping sites such as nano-sized precipitates to fix hydrogen or to at least reduce its diffusivity. (iii) Reinforcement of the grain boundary cohesion to counteract the deleterious effect of hydrogen.

Figure 15 highlights the prior austenite grain size effect on the time to delayed fracture in typical press-hardening steels. The grain size was in this case adjusted by the heating conditions before quenching and was thus not related to specific alloying. It is obvious, that martensitic steel in the $2000 \mathrm{MPa}$ class is much more sensitive to hydrogen-induced delayed cracking than steel in the $1500 \mathrm{MPa}$ class. Higher manganese addition is likewise detrimental to delayed cracking resistance. Therefore, emphasizing on manganese alloying for obtaining high hardenability is not a recommended option. Grain refinement, however, brings an improvement in all cases. Nevertheless, the delayed cracking resistance of standard $32 \mathrm{MnB} 5$ even with finest prior austenite grain size is too low for safe application in components.

The effect of Mo and Mo-Nb alloy additions to standard $32 \mathrm{MnB} 5$ is demonstrated in Fig. 16. The grain sizes in these modified alloys are in the range of 4-6 $\mu \mathrm{m}$. Adding $0.15 \%$ Mo results already in a substantial increase in the

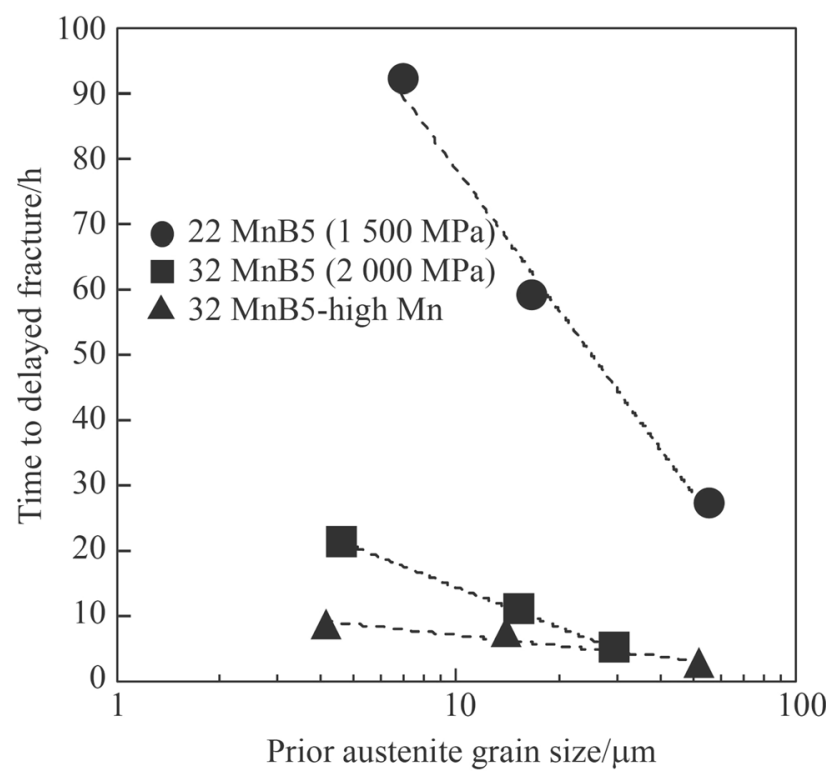

Fig. 15 Effects of prior austenite grain size on the time to delayed fracture in standard manganese-boron alloyed press hardened steels (standard Mn: $1.2 \%$, high-Mn: $2.5 \%$ ) time to delayed fracture and again a synergy between Mo and $\mathrm{Nb}$ becomes evident. The improvement is more pronounced at the higher molybdenum level of $0.5 \%$. The synergy of $0.5 \% \mathrm{Mo}$ and $0.05 \% \mathrm{Nb}$ makes the $2000 \mathrm{MPa}$ steel approximately twice as resistant against delayed cracking as a conventional $1500 \mathrm{MPa}$ steel. Both, Mo and $\mathrm{Nb}$ contribute to grain refinement in the prior austenite microstructure. The larger part of the property gain obviously relates not to grain refinement but to stronger grain boundary cohesion. Molybdenum is known to provide that effect. The synergy with niobium relates to an enhanced amount of ultra-fine precipitates forming in the steel before quenching. These precipitates consisting basically of $\mathrm{NbC}$ can act as efficient hydrogen trap [39]. Analysis by transmission electron microscopy indeed revealed that the area density of ultra-fine niobium precipitates was boosted by the addition of $0.15 \%$ Mo (see Fig. 17), thus severely enhancing the number of hydrogen trapping sites. More intricate beneficial effects of molybdenum in retarding delayed fracture relate to: (i) reduction in the mobility of dislocations initiated from the crack tip, (ii) reduction of pile-up stress of dislocations at the grain boundary, (iii) vacancy trapping obstructing the formation of vacancy clusters and micro-voids.

These effects impede the underlying mechanisms of hydrogen-induced crack initiation and propagation, which will not be discussed in detail in the present context.

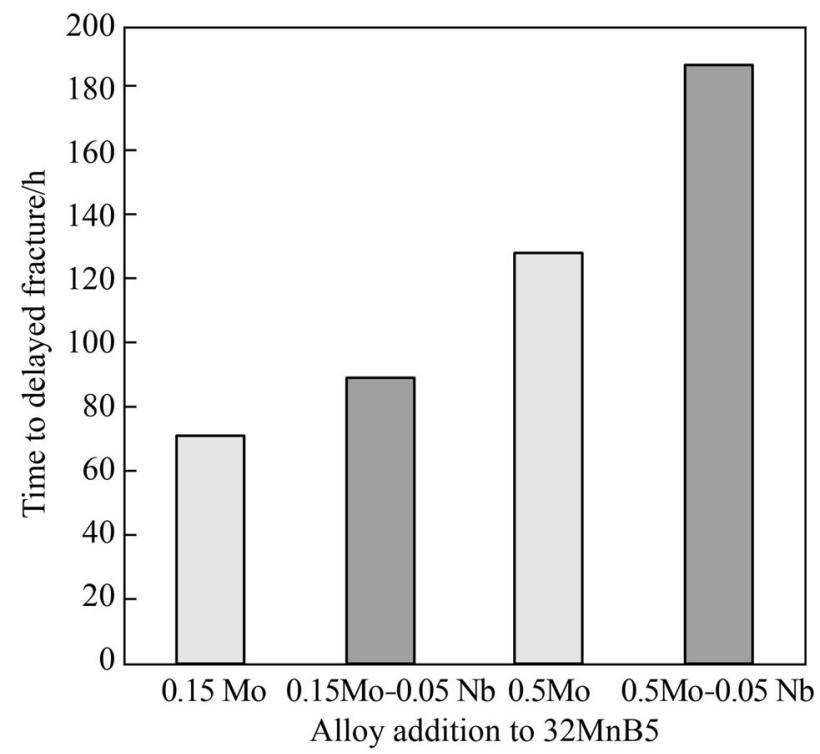

Fig. 16 Effects of molybdenum and niobium additions to standard $32 \mathrm{MnB} 5$ on the time to delayed fracture in press-hardened steels $(\mathrm{Mn}$ : $1.2 \%)$ 


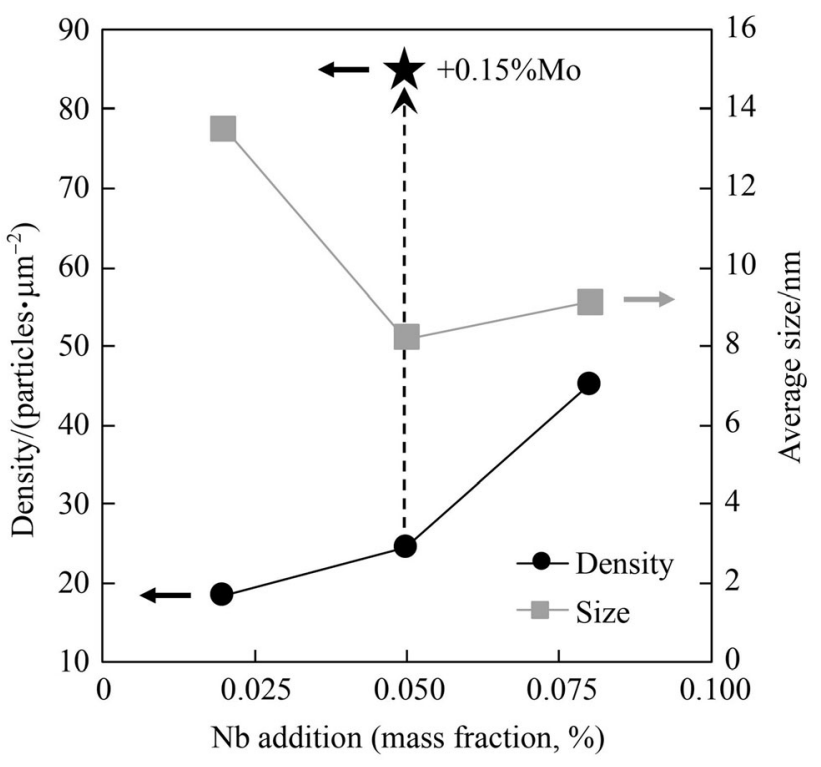

Fig. 17 Average size and area density of ultra-fine NbC precipitates in press hardened steel as analyzed by transmission electron microscopy (the effect of $0.15 \% \mathrm{Mo}$ addition on the $\mathrm{NbC}$ particle density is indicated for a $0.05 \% \mathrm{Nb}$ alloyed steel)

\subsection{Application examples of martensitic steels}

Martensitic steels are particularly interesting for application in hoisting equipment. Crane booms demand the lowest possible dead weight for lifting heavy loads with a long reach. For that purpose, steel grades with minimum yield strength of 960-1 $300 \mathrm{MPa}$ are nowadays being used. Taking a conventional grade 50 steel (355 MPa, yield strength) as a reference, substitution by a $960 \mathrm{MPa}$ grade allows reducing the material gage and thus the component weight by more than $70 \%$. Regarding a typical butt-welding situation with a $\mathrm{V}$-shape bevel, the weld seam volume will be reduced by over 90\% [1]. Accordingly, component handling and manufacturing become much more efficient. However, it must be mentioned that the weldability of ultra-high strength steels is more demanding in terms of filler material as well as skill level of the welder. Another important consideration relates to the heat-affected zone properties after welding [40]. The heat input by the welding process leads to peak temperatures of over $1300{ }^{\circ} \mathrm{C}$ close to the fusion line and induces significant modification of the original microstructure. This results in soft zones having a yield strength lower than that of the base material as well as the fusion line. Such soft zones bear the risk of localized premature yielding under service load conditions. An appropriate alloy concept using molybdenum and niobium reduces or completely avoids heat-affected zone softening. This is related to the tempering resistance provided by these alloying elements as was demonstrated by Fig. 14. For that reason, molybdenum is added up to $0.7 \%$ in such steels while niobium is usually limited to $0.05 \%$. The carbon equivalent (CE IIW) of such steels is typically in the range of 0.5-0.6, while the absolute carbon content remains below $0.2 \%$. Components used for equipment in the mining and mineral processing industry typically require high resistance against wear. Correspondingly, the steel should have high hardness which is achieved by raising the carbon content. Toughness is not only needed due to likely high-impact loading under service conditions, but also to further improve wear resistance [41, 42]. Molybdenum alloying, often in combination with niobium, provides the required property spectrum of strength, hardness and toughness. The production of thin-gage martensitic steel has been steadily increasing over the last years due to the intensive use of press-hardened components in car bodies. Car models utilize $1500 \mathrm{MPa}$ press hardening steel (22MnB5) to an amount of up to $40 \%$ of the total body weight. For enabling further weight saving or crash resistance, steelmakers are developing press-hardening steel in the $2000 \mathrm{MPa}$ class (34MnB5). Qualification tests by carmakers confirmed that sufficient delayed cracking resistance required alloying of molybdenum. First $2000 \mathrm{MPa}$ class products in the market indeed rely on a combined molybdenum and niobium addition to standard 34MnB5 steel [43].

\section{Alloy concepts and processing routes for multi- phase steels}

HSLA steels offer a very good compromise between strength, toughness and weldability. However, some applications require higher elongation than that HSLA steel can provide at comparable strength level. Other applications need higher strength than that offered by HSLA steels yet having more ductility than martensitic steels. This product range of steels having tensile strengths from $600 \mathrm{MPa}$ up to $1200 \mathrm{MPa}$ and high ductility is covered by so-called multi-phase steels. In this concept a particular combination of strong phases and ductile phases is adjusted by specific thermo-mechanical treatment.

\subsection{Dual-phase steel design and applications}

Microstructural design consists of a ductile matrix, typically ferrite, containing a dispersed second phase of usually martensite and/or bainite has been existing for several decades and is most prominently represented by the dualphase steel family, which can reach tensile strength up to about $1000 \mathrm{MPa}$. The vast majority of dual-phase steel production is cold-rolled to gages below $2 \mathrm{~mm}$ and used for car body components. Hot-rolled dual-phase steel in the gage range of 3-6 $\mathrm{mm}$ is being used almost exclusively for 
manufacturing of vehicle wheels. More recently, however, heavier-gaged hot-rolled dual-phase steel gained interest in pipeline applications. While the current top grade for pipe manufacturing is X80, as discussed in Sect. 2, future projects investigate the feasibility of grade X90 or X100. Enhancing strength further based on the established X80 alloy platform would result in rather low elongation of higher strength steel and thus not allow the implementation of strain-based design concepts to pipeline construction. A dual-phase microstructure can solve this conflict providing sufficient elongation at $\mathrm{X} 90-\mathrm{X} 100$ strength level. The challenge for the steel producer is to rather precisely adjust the two microstructural phases, being ferrite and martensite, in terms of volume fraction, grain size and spatial distribution under the available processing conditions.

Molybdenum alloying plays a prominent role in achieving a dual-phase microstructure, especially in hotrolled products such as strip and plate. Dual-phase steel production requires initial transformation of austenite into ferrite, enrichment of the remaining austenite with carbon and final fast-cooling converting the carbon enriched austenite into martensite. This process is schematically shown in Fig. 18 for hot strip production [44]. Strip speed, length of the run-out table and cooling conditions determine the acceptable processing window for forming a sufficient volume fraction of ferrite. Within this time frame, pearlite formation must be suppressed. A two-step cooling strategy is the preferred approach since it allows better control of the ferrite phase share while requiring lower alloy content. The metallurgical functionality of molybdenum is two-fold in this respect [45, 46]. Firstly, it moderately delays ferrite formation but strongly obstructs pearlite formation (see Fig. 19). In that respect

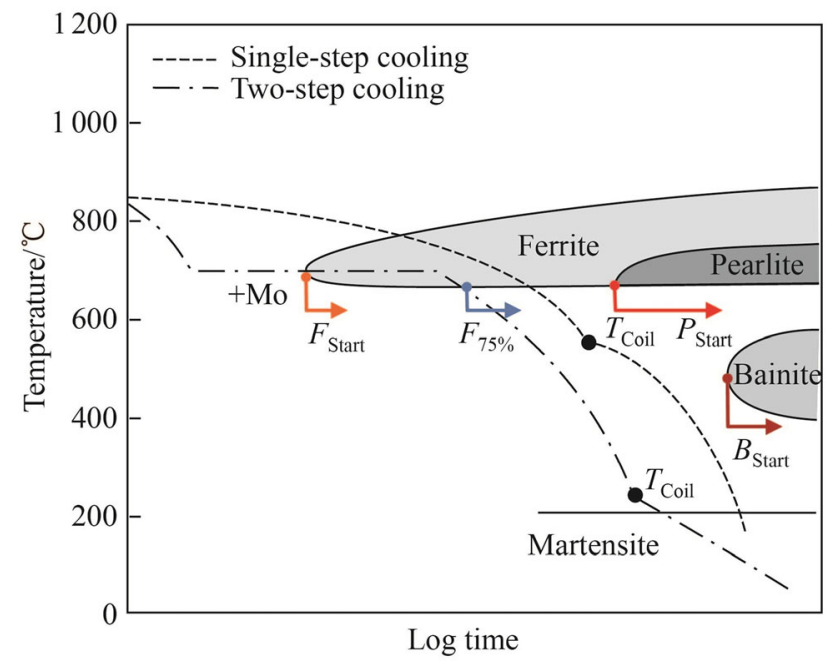

Fig. 18 Alloying and processing strategies for producing hot-rolled dual-phase steel with ferrite-martensite microstructure (the effects of molybdenum are schematically indicated) molybdenum widens the time window for ferrite formation. Secondly, molybdenum obstructs the decay of the carbonenriched austenite into bainite. In strip mills allowing twostep cooling strategy, the addition of around $0.15 \% \mathrm{Mo}$ is sufficient for robust production of dual-phase steel. Flexibility of the cooling strategy is higher when producing dual-phase steel plate products, since the plate is at rest in the cooling device. The difficulty in this case relates more to the heavy gage of the product, making that the cooling rate at the plate surface is much higher than in the core. Molybdenum at a higher addition level can favorably mitigate the phase formation in this situation as well.

The production of X100 plate, for instance, can be realized by using $0.07 \% \mathrm{C}-0.08 \% \mathrm{Nb}-0.25 \% \mathrm{Mo}$ base chemistry. After TMCP rolling, the plate is cooled to a temperature in the intercritical region, i.e., between $A_{\mathrm{r} 3}$ and $A_{\mathrm{r} 1}$, to allow ferrite formation and carbon partitioning followed by final quenching [26]. Polygonal ferrite grains decorate the periphery of former austenite pancakes while a finer-grained mixture of nonpolygonal ferrite and martensite develops inside. This approach requires the advanced processing capabilities of a modern plate mill. The particularly fine-grained structure of Mo-Nb alloyed steel (see Fig. 20) thereby facilitates the partitioning of carbon by reducing the distance for carbon to diffuse from newly formed ferrite to remaining austenite grains.

The adjustment of a dual-phase microstructure in coldrolled steel is nowadays primarily done by using the hotdip galvanizing process. The integrated recrystallization annealing cycle prior to galvanizing is performed in the

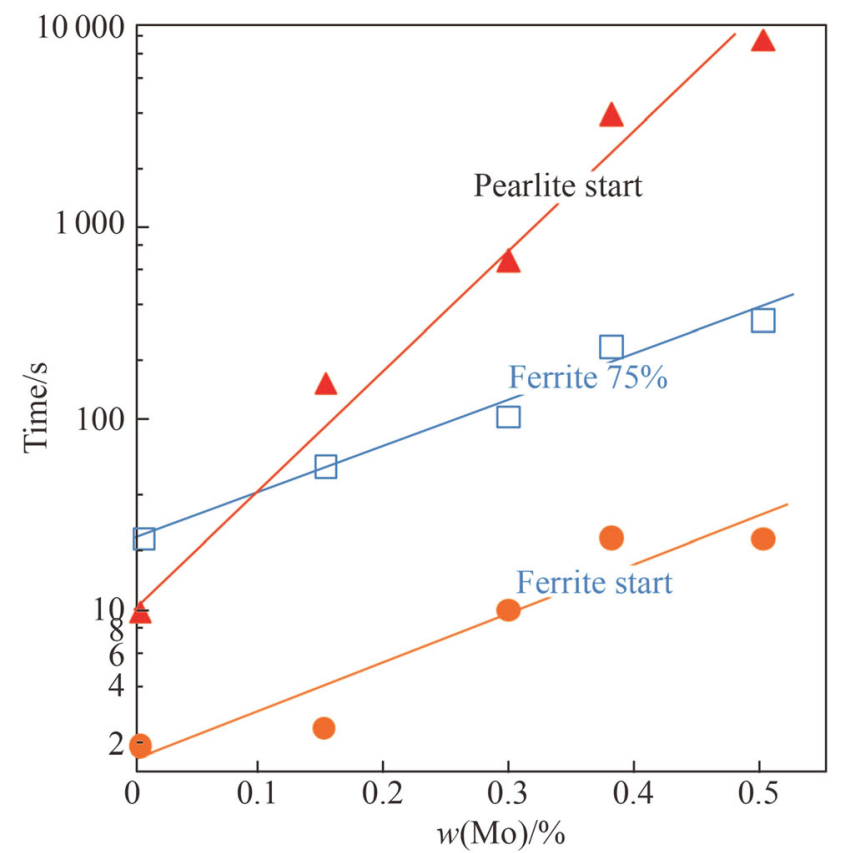

Fig. 19 Influences of molybdenum alloy content on the delay of ferrite and pearlite formation times 


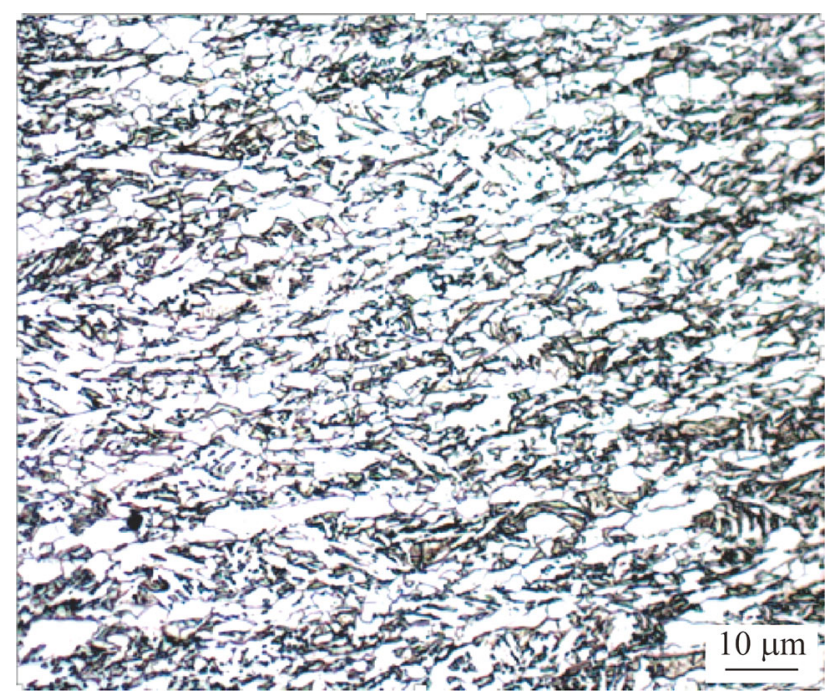

Fig. 20 Dual-phase microstructure of Mo-Nb alloyed X100 pipe steel

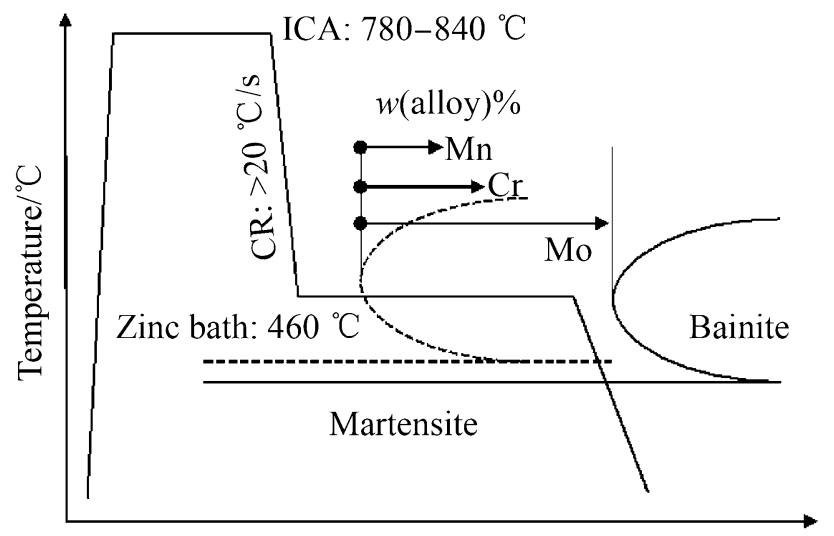

Time/s

Fig. 21 Time-temperature characteristic of hot-dip galvanizing cycle and effect of alloying elements on suppressing bainite formation during isothermal holding in the zinc bath

inter-critical temperature range between $A_{\mathrm{c} 1}$ and $A_{\mathrm{c} 3}$. A sufficient amount of new austenite is formed by dissolving the pearlite present in the original cold-rolled steel. After the inter-critical annealing stage, the steel strip is fast cooled to a temperature of around $460{ }^{\circ} \mathrm{C}$ before entering the liquid zinc bath followed by final cooling. It is thereby important that the meta-stable austenite does not transform into bainite during the passage through the liquid zinc bath. Again, the retardation of bainite formation by molybdenum alloying allows enhancing the robustness of this process (see Fig. 21). This bainite-retarding effect is relatively stronger for molybdenum as compared to manganese or chromium [47].

\subsection{Multi-phase steel containing retained austenite}

Increased ductility in ultra-high strength steel requires a microstructural design having strong phases such as martensite or bainite representing the majority phase and dispersed retained austenite islands being the minority phase [48]. The austenite phase provides ductility to the strong matrix and in-situ transforms into martensite upon applied deformation, known as the transformation-induced plasticity (TRIP) effect. The strain-induced martensite phase results in substantial work-hardening of the steel. A practical way of producing such steel is to quickly cool the austenitic microstructure, being present after either hot rolling or a prior annealing treatment, into the bainite forming temperature range followed by isothermal holding $[49,50]$. This treatment, also known as austempering, allows formation of carbide-free bainite. The carbon is partitioned from the advancing bainite phase to the remaining austenite phase. Part of this austenite fraction is carbon-enriched high enough to remain meta-stable at room temperature. Sufficiently high additions of silicon and/or aluminum help suppressing the precipitation of cementite during bainite growth. However, both alloying elements are strong ferrite promotors. The unwanted formation of any ferrite phase fraction will significantly lower the strength of the steel. Molybdenum alloying effectively retards premature ferrite formation especially at lower quenching rates. During isothermal holding in the bainite temperature range molybdenum is retarding the phase transformation kinetics as well. Since carbon diffusion is already relatively slow in this temperature range, the retarded transformation kinetics provides more time for completing carbon partitioning. Molybdenum segregates to grain and lath boundaries attracting carbon atoms. The resulting high solute carbon concentration at the periphery

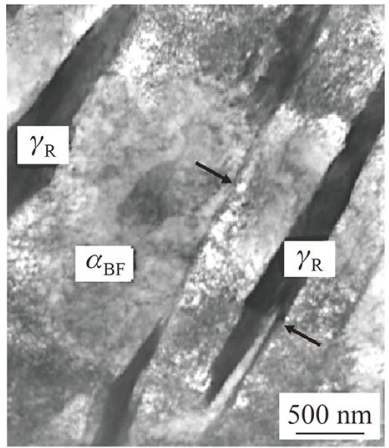

(a)

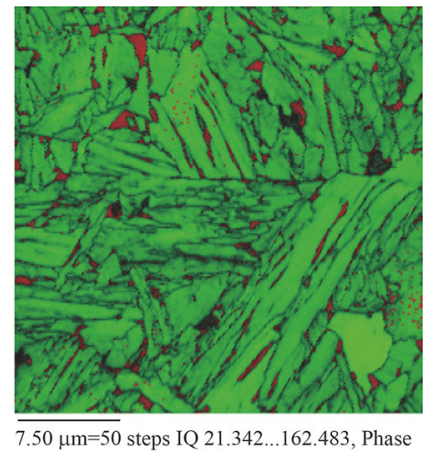

(b)
Fig. 22 Formation of retained austenite films a microstructure of a TRIP bainitic-ferrite steel $\left(\alpha_{\mathrm{BF}}\right)$ showing retained austenite $\left(\gamma_{\mathrm{R}}\right)$ films along the bainitic sheaf boundaries (arrows) b identification of phases by electron back scatter diffraction (EBSD) analysis (green: bainiticferrite, red: retained austenite) 
of such carbide-free bainite needles results in the formation of retained austenite films (see Fig. 22) [51].

Steel processed to a microstructure comprising a bainitic matrix containing retained austenite has been commercialized for automotive applications under the name TBF (TRIP Bainitic-Ferrite) steel. Due to the combination of ultra-high strength and good elongation TBF steel has high energy absorption capacity and is well-suited for crashresistant components in the lateral structure of the car body.

Further developments aim at combining a martensitic matrix with retained austenite by employing a process called quenching \& partitioning (Q\&P) [52]. Here, austenite is immediately quenched to below the martensitestart temperature, yet cooling is interrupted before full martensite transformation. Fast reheating to a higher temperature enables partitioning of carbon from the initially formed martensite to enrich still existing austenite. That austenite, depending on the level of carbon enrichment, forms fresh martensite upon final cooling or remains as metastable retained austenite. This approach is principally limited to thin-gage strip products and requires specific adaptations of continuous annealing lines or galvanizing lines to allow fast reheating. Alloying concepts, including the benefits of molybdenum alloying, are similar to those for TBF steel [53]. Like martensitic steels, TBF as well as Q\&P steels are sensitive to hydrogen embrittlement. Hence, the same beneficial effects of molybdenum alloying preferably in combination with niobium micro-alloying apply.

Recently such microstructural concepts have also been considered for production of ultra-high strength plate steel with heavier gage [54-57]. Yet, alloy concept and process have important differences compared to thin sheet steel. The relatively high carbon content of $0.2 \%-0.3 \%$ as practiced in TBF and Q\&P steels is not desirable in plate products due to weldability and toughness concerns. While a TBF-like process would be possible in plate production, in-line $\mathrm{Q} \& \mathrm{P}$ processing is not. Instead, process variants with two inter-critical heat treatment steps and final

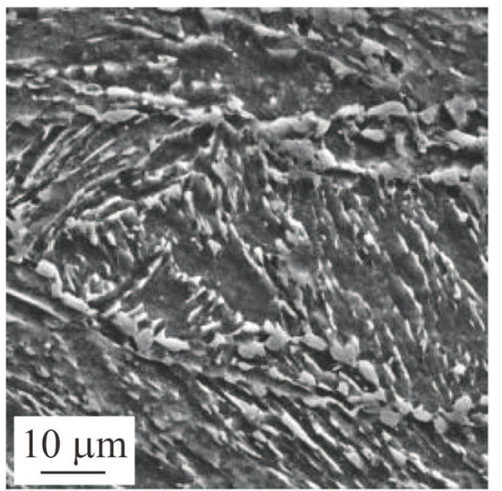

(a)

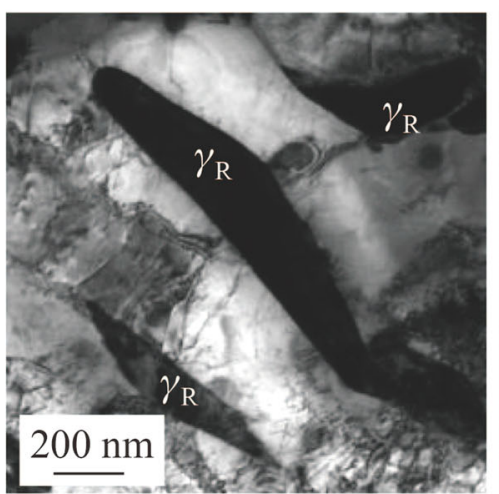

(b)

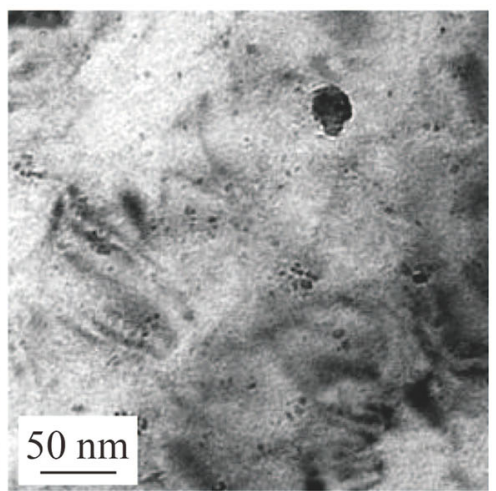

(c)

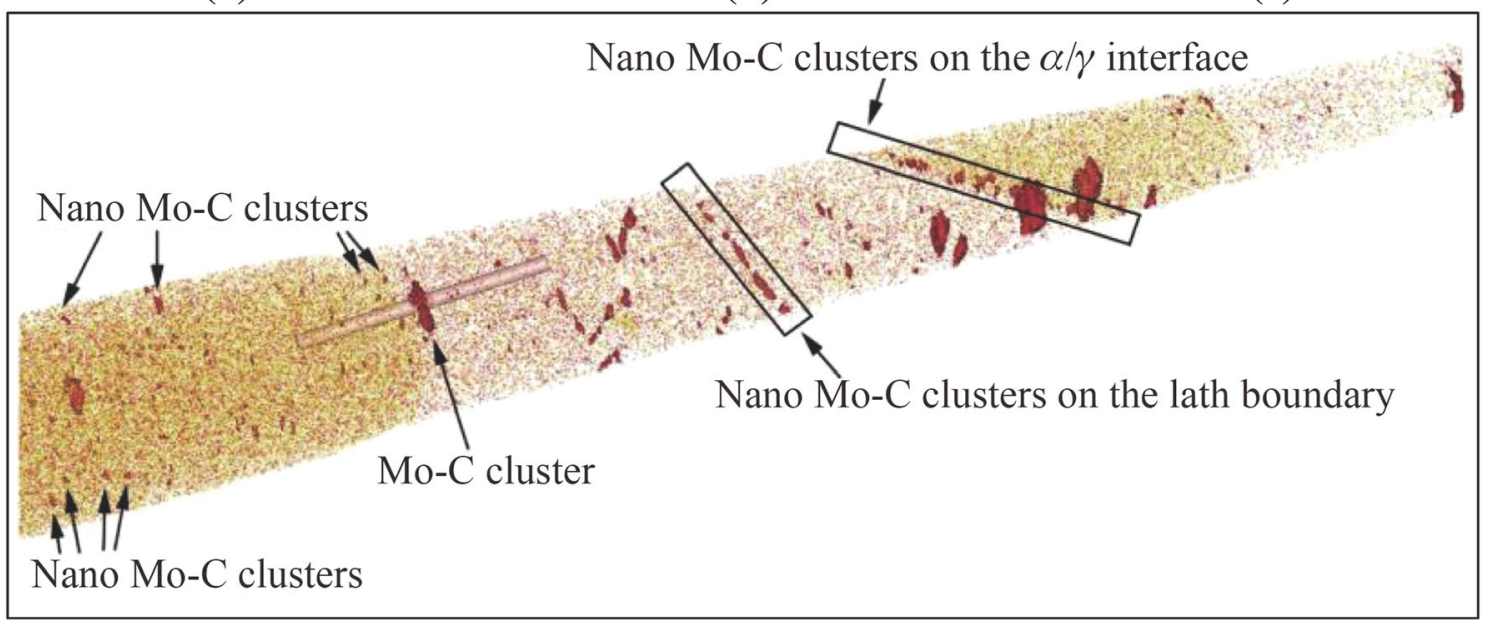

(d)

Fig. 23 Microstructural evolution during processing of steel according to the $\mathrm{M}^{3}$ concept a carbon-enriched bainite/martensite islands dispersed in a ferritic matrix, $\mathbf{b}$ carbon-enriched reversed austenite $\left(\gamma_{\mathrm{R}}\right)$ formed after second inter-critical annealing stage, $\mathbf{c}$ nano-sized precipitates formed after final tempering cycle, $\mathbf{d}$ atom probe tomography of final microstructure showing molybdenum segregation at lath and phase boundaries and Mo-C clustering 
Table 2 Mechanical properties of C-Si-Mn-Ni-Cu-Mo-Nb steel before and after $\mathrm{M}^{3}$ heat treatment cycle

\begin{tabular}{llllll}
\hline Condition & $Y_{\mathrm{S}} / \mathrm{MPa}$ & $T_{\mathrm{S}} / \mathrm{MPa}$ & $A_{50} / \%$ & $A_{\mathrm{U}} / \%$ & $\mathrm{CVN}-40^{\circ} \mathrm{C} / \mathrm{J}$ \\
\hline As hot rolled & 973 & 1265 & 14.4 & 3.8 & 35 \\
$\mathrm{M}^{3}$ heat treated & 977 & 1037 & 20.4 & 9.0 & 66 \\
\hline
\end{tabular}

tempering have been explored. The resulting microstructure, propagated in China as " $\mathrm{M}^{3}$ concept", consists of meta-stable austenite in a multi-phase matrix strengthened by multi-scale precipitation (see Fig. 23) [58]. The first inter-critical annealing step forms a dual-phase microstructure consisting of carbon-enriched bainite/martensite islands dispersed in a ferritic matrix (see Fig. 23a), which is grain-size controlled by NbC precipitates. The second inter-critical treatment, executed at lower temperature, further enriches reversed austenite with carbon to become meta-stable at room temperature and induces co-precipitation of $\mathrm{Nb}, \mathrm{Cu}$ and $\mathrm{Mo}$ (see Fig. 23b). The third step applies a sub-critical tempering treatment to this multi-phase microstructure to further enhance precipitation strengthening. Suitable alloy concepts limit carbon to the range of $0.1 \%-0.15 \%$. Additions of $2 \%-3 \% \mathrm{Mn}$ and $0.5 \%-1.0 \% \mathrm{Ni}$ help stabilizing reversed austenite. Increased amounts of silicon and aluminum promote carbon partitioning and prevent cementite precipitation. Niobium, vanadium and copper additions provide precipitation on different scales for grain size control and strengthening. Molybdenum alloying in the range of $0.3 \%-0.4 \%$ deploys its versatile effects as discussed already before. A steel in that composition range contains approximately $22 \%$ retained austenite in the microstructure after the heat treatment sequence. The evolution of the mechanical properties by the heat treatment is detailed in Table 2 showing high ductility for a steel in the $1000 \mathrm{MPa}$ class.

\section{Conclusions}

The use of modern high-performance steels enables significant improvements in design of structures, efficiency of manufacturing, durability of equipment, safety, cost reduction and lifecycle sustainability. The production of such steels requires state-of-the-art steel rolling and heat treatment facilities in combination with suitable alloying concepts. Molybdenum was shown to be one of the most effective and versatile alloying elements by enabling robust processing of such steel grades as well as by providing superior application properties. Particularly the remarkable effect of molybdenum, ideally in synergy with niobium, in improving the resistance against hydrogen-induced cracking in ultra-high strength steels is an issue of intensive ongoing research activities.

Open Access This article is licensed under a Creative Commons Attribution 4.0 International License, which permits use, sharing, adaptation, distribution and reproduction in any medium or format, as long as you give appropriate credit to the original author(s) and the source, provide a link to the Creative Commons licence, and indicate if changes were made. The images or other third party material in this article are included in the article's Creative Commons licence, unless indicated otherwise in a credit line to the material. If material is not included in the article's Creative Commons licence and your intended use is not permitted by statutory regulation or exceeds the permitted use, you will need to obtain permission directly from the copyright holder. To view a copy of this licence, visit http://creativecommons. org/licenses/by/4.0/.

\section{References}

1. Mohrbacher H (2013) Reverse metallurgical engineering towards sustainable manufacturing of vehicles using $\mathrm{Nb}$ and Mo alloyed high performance steels. Adv Manuf 1:28-41

2. Mohrbacher H, Spöttl M, Paegle J (2015) Innovative manufacturing technology enabling light weighting with steel in commercial vehicles. Adv Manuf 3:3-18

3. Isasti N, Jorge-Badiola D, Taheri ML et al (2014) Microstructural features controlling mechanical properties in $\mathrm{Nb}$-Mo microalloyed steels. Part I: yield strength. Metall Mat Trans A 45:4960-4971

4. Isasti N, Jorge-Badiola D, Taheri ML et al (2014) Microstructural features controlling mechanical properties in Nb-Mo microalloyed steels. Part II: impact toughness. Metall Mat Trans A 45:4972-4982

5. Isasti N, Jorge-Badiola D, Taheri ML et al (2013) Phase transformation study in Nb-Mo microalloyed steels using dilatometry and EBSD quantification. Metall Mat Trans A 44:3552-3563

6. Pavlina EJ, Speer JG, van Tyne CJ (2012) Equilibrium solubility products of molybdenum carbide and tungsten carbide in iron. Script Mater 66(5):243-246

7. Hoerner M, Speer J, Eberhart M (2017) Comparison of Ab-initio solute-boundary binding energies and experimental recrystallization data in austenite for solute $\mathrm{Nb}$ and other elements. ISIJ Int 57(10):1847-1850

8. Hepburn DJ, MacLeod E, Ackland GJ (2014) Transition metal solute interactions with point defects in austenitic iron from first principles. Phys Rev B 92:014110

9. Li YJ, Ponge D, Choi P et al (2015) Segregation of boron at prior austenite grain boundaries in a quenched martensitic steel studied by atom probe tomography. Script Mater 96:13-16

10. Eckstein HJ, Fennert M, Ohser J (1993) Application of thermodynamic computations to the solution behaviour of niobium and vanadium carbonitrides. Steel Res 64(3):143-147 
11. Lee SJ, Matlock D, van Tyne C (2011) An empirical model for carbon diffusion in austenite incorporating alloying element effects. ISIJ Int 51(11):1903-1911

12. Medina SF, Mancilla JE (1996) Influence of alloying elements in solution on static recrystallization kinetics of hot deformed steels. ISIJ Int 36(8):1063-1069

13. Akben MG, Bacroix B, Jonas JJ (1983) Effect of vanadium and molybdenum addition on high temperature recovery, recrystallization and precipitation behavior of niobium-based microalloyed steels. Acta Metall 31(1):161-174

14. Togashi F, Nishizawa T (1976) Effect of alloying elements on the mobility of ferrite/austenite interface. J Jpn Inst Metals 40(1):12-21

15. Tither G, Lavite M (1976) Beneficial stress-strain behavior of moly-columbium steel line pipe. JOM 27:15-23

16. Funakawa Y, Shiozaki T, Tomita K et al (2004) Development of high strength hot-rolled sheet steel consisting of ferrite and nanometer-sized carbides. ISIJ Int 44(11):1945-1951

17. Engberg G, Lissel L (2008) A physically based microstructure model for predicting the microstructural evolution of a C-Mn steel during and after hot deformation. Steel Res Int 79:47-58

18. Yen HW, Chen PY, Huang CY et al (2011) Interphase precipitation of nanometer-sized carbides in a titanium-molybdenumbearing low-carbon steel. Acta Mater 59:6264-6274

19. Larzabal G, Isasti N, Rodriguez-Ibabe JM (2018) Precipitation strengthening by induction treatment in high strength low carbon microalloyed hot-rolled plates. Metall Mat Trans A 49:946-961

20. Huang BM, Yang JR, Yen HW et al (2014) Secondary hardened bainite. Mater Sci Technol 30(9):1014-1023

21. Belanger P, Hall J, Coryell J et al (2013) Automotive body presshardened steel trends. In: Proceedings of the international symposium on the new developments of advanced high-strength steel, 23-27 June 2013, Vail, Colorado, USA, pp 239-250

22. Bian J, Mohrbacher H (2013) Novel alloying design for press hardening steels with better crash performance. In: Proceedings of the international symposium on the new developments of advanced high-strength steel, 23-27 June 2013, Vail, Colorado, USA, pp 251-262

23. Olsson R, Haglund N (1991) Cost effective fabrication of submarines and mobile cranes in high performance steels. Int $\mathrm{J}$ Join Mater 3:120-128

24. Shang C, Guo F (2018) The state of the art of long-distance gas pipeline in China. Gas Energy 1:24-29

25. Piette M, Dubrulle-Prat E, Perdrix C et al (2001) Effect of $0-0.1 \% \mathrm{Nb}$ additions on mechanical properties of plates processed by thermomechanically controlled processing and accelerated cooling. Iron Mak Steelmak 28(2):175-179

26. Subramanian SV, Yang Y (2014) On austenite conditioning and recrystallization control of higher grade linepipe steels (X100) with niobium and molybdenum additions. In: Mohrbacher $\mathrm{H}$ (ed) Fundamentals and applications of $\mathrm{Mo}$ and $\mathrm{Nb}$ alloying in high performance steels, vol 1, TMS, pp 3-22

27. Bian J, Mohrbacher H, Zhang JS et al (2015) Application potential of high performance steels for weight reduction and efficiency increase in commercial vehicles. Adv Manuf 3:27-36

28. Kage I, Matsui K, Kawabata F (2005) Minimum maintenance steel plates and their application technologies for bridge-life cycle cost reduction technologies with environmental safeguards for preserving social infrastructure assets. JFE Tech Rep 5:37-44

29. Walp MS, Speer JG, Matlock DK (2004) Fire-resistant steels. Adv Mater Process 162:34-36

30. Mizutani Y, Ishibashi K, Yoshi K et al (2004) 590 MPa class fireresistant steel for building structural use. Nippon Steel Tech Rep 90:45-52

31. Sugimoto K (2009) Fracture strength and toughness of ultra-high strength TRIP aided steels. Mater Sci Technol 25:1108-1117
32. Nagumo M (2001) Function of hydrogen in embrittlement of high-strength steels. ISIJ Int 41:590-598

33. Degenkolbe J, Mahn J, Muesgen B et al (1987) Experience gained in the accelerated cooling of plate directly after rolling. Thyssen Tech Rep 87(1):41-55

34. Takaki S, Ngo-Huynh KL, Nakada N et al (2012) Strengthening mechanism in ultra low carbon martensitic steel. ISIJ Int 52:710-716

35. Grossman MA (1942) Hardenability calculated from chemical composition. Trans Am Inst Min Metall Petrol Eng 150:227-259

36. Maki T, Tsuzaki K, Tamura I (1980) The morphology of the strengthening of lath martensite in steels. Trans Iron Steel Inst Jpn 20:207-215

37. Hannula J, Kömi J, Porter D et al (2017) Effect of boron on the strength and toughness of direct-quenched low-carbon niobium bearing ultra-high-strength martensitic steel. Metall Mat Trans A 48:5344-5356

38. Mohrbacher H (2018) Property optimization in as-quenched martensitic steel by molybdenum and niobium alloying. Metals 8:234. https://doi.org/10.3390/met8040234

39. Ohnuma M, Suzuki J, Wei FG et al (2008) Direct observation of hydrogen trapped by $\mathrm{NbC}$ in steel using small-angle neutron scattering. Script Mater 58:142-145

40. Mohrbacher H (2019) Metallurgical effects of niobium and molybdenum on heat-affected zone toughness in low-carbon steel. Appl Sci 9(9):1847. https://doi.org/10.3390/app9091847

41. Ahlblom B, Hansson P, Narström T (2007) Martensitic structural steels for increased strength and wear resistance. Mater Sci Forum 539(543):4515-4520

42. Ishikawa N, Ueda K, Mitao S et al (2011) High-performance abrasion-resistant steel plates with excellent low-temperature toughness. In: Proceedings of international symposium on the recent developments in plate steels. AIST, Winter Park, pp 81-91

43. Schmit F, Cobo S (2016) New press hardened steels and tailored blank applications. In: Materials in Car Body Engineering 2016, Bad Nauheim, Germany, 9-11 May 2016

44. Avtar R, Jha BK, Saxena A et al (1986) An as hot rolled approach to production of molybdenum and chromium microalloyed dual phase steels. Trans ISIJ 26:822-828

45. Coldren AP, Ellis GT (1980) Using CCT Diagrams to optimize the composition of an as-rolled dual-phase steel. J Metals 32(3):41-48

46. Geib MD, Matlock DK, Krauss G (1980) The effect of intercritical annealing temperature on the structure of niobium microalloyed dual- phase steel. Metall Trans A 11:1683-1689

47. Irie T, Satoh S, Hashiguchi K et al (1981) Metallurgical factors affecting the formability of cold-rolled high strength steel sheets. Trans ISIJ 21(11):793-801

48. Sugimoto K (2009) Fracture strength and toughness of ultra-high strength TRIP aided steels. Mater Sci Technol 25(9):1109-1117

49. Hashimoto S, Ikeda S, Sugimoto K et al (2004) Effects of $\mathrm{Nb}$ and Mo addition to $0.2 \% \mathrm{C}-1.5 \% \mathrm{Si}-1.5 \% \mathrm{Mn}$ steel on mechanical properties of hot rolled TRIP-aided steel sheets. ISIJ Int 44(9):1590-1598

50. Sugimoto K, Murata M, Muramatsu M et al (2007) Formability of C-Si-Mn-Al-Nb-Mo ultra high-strength TRIP-aided sheet steels. ISIJ Int 47(9):1357-1362

51. Kobayashi J, Ina D, Yoshikawa N et al (2012) Effects of the addition of $\mathrm{Cr}$, Mo and $\mathrm{Ni}$ on the microstructure and retained austenite characteristics of $0.2 \% \mathrm{C}-\mathrm{Si}-\mathrm{Mn}-\mathrm{Nb}$ ultrahigh-strength TRIP-aided bainitic ferrite steels. ISIJ Int 52(10):1894-1901

52. Speer JG, Matlock DK, de Cooman BC et al (2003) Carbon partitioning into austenite after martensite transformation. Acta Mater 51:2611-2622

53. Yan S, Liu X, Liang T et al (2019) Effect of micro-alloying elements on microstructure and mechanical properties in C-Mn- 
Si quenching and partitioning (Q\&P) steels. Steel Res Int 90:1800257. https://doi.org/10.1002/srin.201800257

54. Sun XJ, Li ZD, Yong QL et al (2012) Third generation high strength low alloy steels with improved toughness. Sci China Technol Sci 55(7):1797-1805

55. Yuan S, Shang C, Xie Z et al (2018) Impact of intercritical annealing on retained austenite and toughness of a $460 \mathrm{MPa}$ grade multiphase heavy gauge plate steel. Steel Res Int 89:1800006. https://doi.org/10. 1002/srin.201800006

56. Stewart RA, Speer JG, Thomas BG et al (2018) Process design for quenching and partitioning of plate steels. In: Proceedings of the 2nd international symposium on the recent developments in plate steels, Orlando, AIST, pp 469-475

57. Hernaut P, Ertzibengoa D, de Cooman BC et al (2018) Development of high-performance steel plates at NLMK clabecq. In: Proceedings of the 2nd international symposium on the recent developments in plate steels, Orlando, AIST, pp 139-149

58. Xie ZJ, Xiong L, Han G et al (2018) Thermal stability of retained austenite and properties of a multi-phase low alloy steel. Metals 8(10):807. https://doi.org/10.3390/met8100807

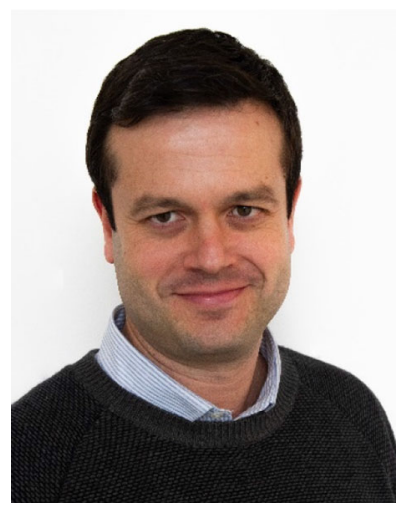

Pello Uranga is the Associate Director of the Materials and Manufacturing Division at CEIT and associate professor at Tecnun (University of Navarra). $\mathrm{He}$ got his $\mathrm{PhD}$ degree in Materials Engineering in 2002 from the University of Navarra. Currently, his research activity is mainly focused on the thermomechanical processing and the microstructural evolution modeling of steels. He has published over 100 technical papers in international journals and conferences, receiving five international awards. He is an active member of the AIST (Association of Iron and Steel Technology) and TMS (The Mineral, Metals and Materials Society) professional associations, as well as university program evaluator for ANECA (Spain) and ABET (USA).

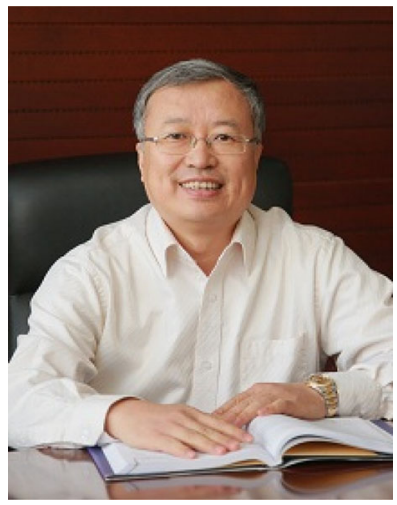

Cheng-Jia Shang is the chief scientist and professor of the Collaborative Innovation Center of Steel Technology, University of Science and Technology Beijing. He was elected as Professional Fellow of the Institute of Materials, Minerals \& Mining (FIMMM), UK, in 2017. His interest is in high-performance steels for marine engineering, oil and gas drilling, storage and transportation, bridge and other infrastructural applications. He is currently Executive Director of Council Member and Secretary-General of the Materials Science Branch of the Chinese Society for Metals, Deputy Director of the Foreign Affairs Committee of the Chinese Society for Metals, Deputy President of Corrosion and Degeneration Division, Society of Automotive Engineers of China Director of the Chinese Materials Research Society.

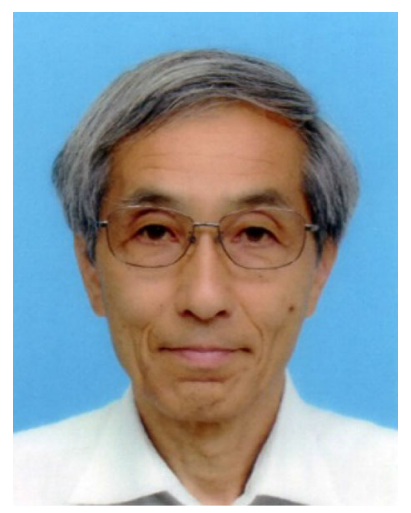

Takehide Senuma is a specially appointed professor of Okayama University in Japan. His major research field is the steel research. He graduated in 1975 with a degree in Mechanical Engineering from the Technical University of Aachen and received a Dr-Ing. degree from the same university. He worked for Nippon Steel as a researcher from 1981 to 1997 and as a general manager from 1998 to 2005. From 2005 to 2015 , he was a professor at Okayama University.

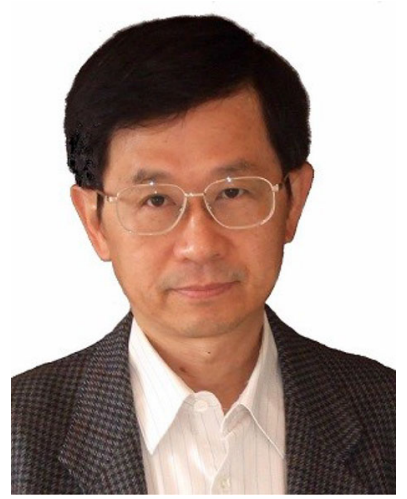

Jer-Ren Yang received Ph.D degree (Materials Science and Metallurgy) from University of Cambridge, England, UK in 1987. In February 1988, he joined the faculty of Department of Materials Science and Engineering, Taiwan University, where he has been a full Professor since August 1993. During the period of August 2007 July 2010, he was the head of the Department. Professor Yang's research interests include phase transformation of steels, crystal geometry and crystal defects. Professor Yang has published some 210 international SCI journal papers in the areas of materials science and engineering.

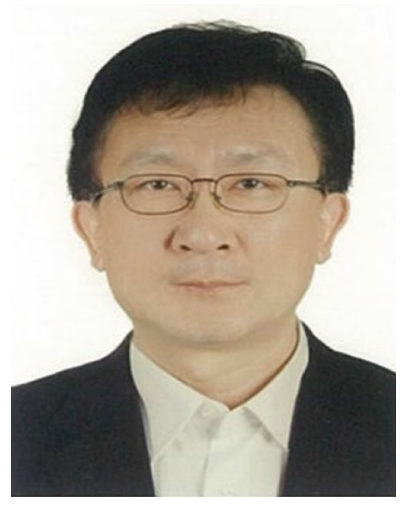

Ai-Min Guo is Chairman of CITIC Dameng Mining Industries Ltd and Vice General Manager/Chief Engineer of CITIC Metal Co., Ltd. He is a Phd in Metal Physical Engineering, Professor-Level Senior Engineer, specialist enjoying the Special Allowance of the State Council, National Candidate of New Century Talents Project, assessor of National Scientific and Technological Progress Award. Dr. Guo has been engaged in product development, production technology and application technology research for boiler and pressure vessels, bridges and buildings, ships, offshore platforms as well as other medium-thick and extra-thick steel plates for a long time. He focuses on researching advanced high-strength steel ductility mechanism, advanced medium and high-carbon steel micro-alloying technology, refinement, strengthening and toughening of structural steel materials and related welding technology. He also has a rich experience in steel structure engineering. 


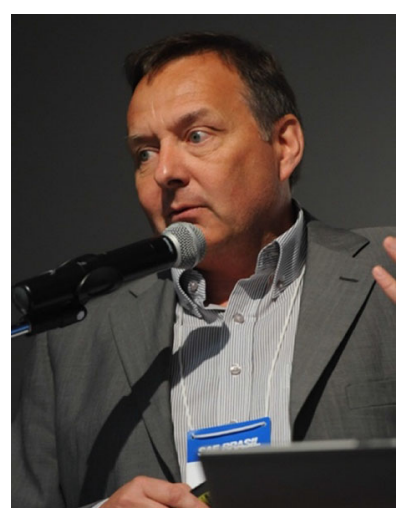

Hardy Mohrbacher specializes in materials and mechanical engineering including steel alloy design and processing, sheet metal forming and welding, automotive body design, non-destructive testing and materials characterization, plus the tribology of hard materials. He has written and co-authored over 200 scientific publication in the respective areas. He has held senior positions within, among others, Fraunhofer Institute for Nondestructive Testing (IZFP), Sidmar (ArcelorMittal Ghent) and ThyssenKrupp (TKTB). $\mathrm{He}$ is an Associate Professor at KU Leuven in Belgium and an
Adjunct Professor at Shanghai University. Since 2007 he is owner and managing director of NiobelCon bvba, a consulting company focusing on steel alloy design, metallurgical processing and steel applications. 